\title{
Biocontrol of Bacterial Fruit Blotch by Bacillus subtilis 9407 via Surfactin-Mediated Antibacterial Activity and Colonization
}

\author{
Haiyan Fan, Zhanwei Zhang, Yan Li, Xun Zhang, Yongming Duan and Qi Wang* \\ Department of Plant Pathology, College of Plant Protection, China Agricultural University, Beijing, China
}

In this study, Bacillus subtilis 9407 showed a strong antibacterial activity against Acidovorax citrulli in vitro and $61.7 \%$ biocontrol efficacy on melon seedlings 4 days post inoculation under greenhouse conditions. To understand the biocontrol mechanism of $B$. subtilis 9407 , identify the primary antibacterial compound and determine its role in controlling bacterial fruit blotch (BFB), a sifAB deletion mutant $(\triangle \operatorname{sif} A B)$ was constructed. The $\triangle S r f A B$ which was deficient in production of surfactin, not only showed

OPEN ACCESS

Edited by:

Yun Chen,

Zhejiang University, China

Reviewed by:

Ömür Baysal,

Muğla University, Turkey

Jia Liu,

Chongqing University of Arts and Sciences, China

${ }^{*}$ Correspondence:

Qi Wang

wangqi@cau.edu.cn

Specialty section:

This article was submitted to

Plant Microbe Interactions,

a section of the journal

Frontiers in Microbiology

Received: 31 May 2017 Accepted: 25 September 2017

Published: 11 October 2017

Citation:

Fan H, Zhang Z, Li Y, Zhang $X$

Duan $Y$ and Wang Q (2017)

Biocontrol of Bacterial Fruit Blotch by

Bacillus subtilis 9407 via

Surfactin-Mediated Antibacterial

Activity and Colonization

Front. Microbiol. 8:1973.

doi: 10.3389/fmicb.2017.01973 almost no ability to inhibit growth of $A$. citrulli but also decreased biofilm formation and reduced swarming motility. Colonization assay demonstrated that $B$. subtilis 9407 could conlonize on melon roots and leaves in a large population, while $\triangle$ srfAB showed a four- to ten-fold reduction in colonization of melon roots and leaves. Furthermore, a biocontrol assay showed that $\triangle s i f A B$ lost the biocontrol efficacy. In summary, our results indicated that surfactin, which consists of C13- to C16-surfactin A was the primary antibacterial compound of $B$. subtilis 9407 , and it played a major role in biofilm formation, swarming motility, colonization and suppressing BFB. We propose that the biocontrol activity of $B$. subtilis 9407 is the results of the coordinated action of surfactin-mediated antibacterial activity and colonization. This study reveals for the first time that the use of a $B$. subtilis strain as a potential biological control agent could efficiently control BFB by producing surfactin.

Keywords: Bacillus subtilis, Acidovorax citrulli, surfactin, antibacterial activity, colonization, biological control

\section{INTRODUCTION}

Bacterial fruit blotch (BFB), caused by the Gram-negative bacterium Acidovorax citrulli (syn. Acidovorax avenae subsp. citrulli), is a serious disease threat to cucurbit crops worldwide (Schaad et al., 2008; Bahar et al., 2009). The pathogen A. citrulli is mainly seed borne and infects organs of cucurbit plant at all stages of growth, resulting in seedling lesions, blight or fruit rot (Hopkins and Thompson, 2002; Popovic and Ivanovic, 2015). Currently, there are few commercially reliable sources of disease resistance to BFB in the cucurbit cultivars, and chemical and physical measures have limited efficacy for disease management (Hopkins et al., 2003; Burdman and Walcott, 2012). Due to difficulties in controlling $\mathrm{BFB}$, and the highly destructive potential of $\mathrm{BFB}$, safe and effective strategies for the prevention and cure for BFB are needed. 
Biological control using microbial antagonists has received a great deal of attention as an alternative and promising measure to control different plant diseases (Daguerre et al., 2014; Chowdhury et al., 2015). Many antagonistic microorganisms including Bacillus spp., Trichoderma spp., Streptomyces spp., Pseudomonas spp., Candida spp. have been exploited and investigated against different plant pathogens (Pérez et al., 2015; Wang et al., 2015). Some microorganisms have been screened and tested the activity against BFB such as Bacillus spp., A. avenae, Pichia anomala, Streptomyces spp. (Fessehaie and Walcott, 2005; Wang et al., 2009; Jiang et al., 2015). Bacillus genus is one of the most frequently studied biological control agents. However, only limited attempts have been made to control BFB using Bacillus. To date, there are no reports about using B. subtilis as a biological control agent against BFB.

Multiple modes of action of Bacillus spp. were reported to contribute to the biological control, including antibiosis, competition, and induce host systemic resistance (Chowdhury et al., 2015). The production of non-ribosomally synthesized antibiotics, especially surfactin, iturin, and fengycin, plays an important role in suppressing diseases (Zeriouh et al., 2011; Guo et al., 2014). The surfactin family is constituted of a seven aminoacid peptide ring linked to a $\beta$-hydroxy fatty acid consisting of 13-16 carbon atoms and synthesized by four biosynthetic genes srfAA, srfAB, srfAC and srfAD (Falardeau et al., 2013). It has been reported that surfactin displays significant inhibitory activity against pathogenic fungi, bacteria, viruses and mycoplasmas (Vollenbroich et al., 1997; Hwang et al., 2008; Wen et al., 2011; Sabate and Audisio, 2013).

Successful colonization of biological control agents on the plants is essential for biocontrol efficacy (Chowdhury et al., 2013; Weng et al., 2013). The ability of Bacillus strains to colonize on plants depends on various factors including swarming motility and biofilm formation (Yaryura et al., 2008; Gao et al., 2016). Swarming motility is a social form of motility that provides flagellated bacteria with the ability to travel rapidly to a nutrient-rich environment and colonize within advantageous colonization locations. Biofilms are multicellular communities of differentiated cells encased by an extracellular matrix, which provide protection against environmental insults and facilitate interactions with other organisms (Kolter and Greenberg, 2006). Studies have revealed that surfactin also plays important roles in biofilm formation, motility, colonization on host plant tissues, and induce plant resistance against pathogens (Ghelardi et al., 2012; Zeriouh et al., 2014; Luo et al., 2015; Rahman et al., 2015). For example, B. subtilis UMAF6614 produces surfactin to ensure well colonize on melon phylloplane and contribute to the biocontrol activity (Zeriouh et al., 2014). Aleti et al. (2016) reported that the surfactin variants with subtle structural differences have varying signal strengths on biofilm formation and root colonization and act specifically on the respective producing strain. However, the role of surfactin in the biocontrol of BFB has not yet been reported.

Bacillus subtilis 9407 was isolated from healthy apples from an infested orchard. In the previous study, we showed that fengycin is the primary antifungal compound of B. subtilis 9407 , and it plays a major role in suppressing apple ring rot disease
(Fan et al., 2017). In this study, we showed that B. subtilis 9407 effectively suppressed $A$. citrulli in vitro and in vivo. However, the primary antimicrobial compound involved in its antibacterial activity and the role of the primary antimicrobial compound in biocontrol are not understood. Lipopeptide crude extracts from B. subtilis 9407 showed strong antibacterial activity against $A$. citrulli MH21. Therefore, we mutated candidate genes for biosynthesis of selected lipopeptide and investigated the antibacterial activity of the mutants against A. citrulli $\mathrm{MH} 21$. Since $\triangle \operatorname{srf} A B$ almost completely lost the ability to inhibit the growth of $A$. citrulli $\mathrm{MH} 21$, we focused on surfactin, indicated it was a mixture of C13- to C16-surfactin A. Then, we investigated the putative contribution of surfactin to the biofilm formation, swarming motility, colonization, and biocontrol abilities of this biocontrol agent. We demonstrated that surfactin was the primary antibacterial compound of B. subtilis 9407, and it played a major role in biofilm formation, swarming motility, colonization and suppressing BFB. We propose that the biocontrol activity of this strain is the results of the coordinated action of antibacterial activity and colonization. The results of our study may provide a new biological control agent for controlling BFB and improve our understanding of the biocontrol mechanism of B. subtilis 9407.

\section{MATERIALS AND METHODS}

\section{Bacterial Strains, Plasmids and Growth Conditions}

The bacterial strains and plasmids used in this study are described in Supplementary Table S1. B. subtilis strains were routinely grown at $37^{\circ} \mathrm{C}$ in Luria-Bertani (LB) medium. For assays of biofilm formation, MSgg medium was used. The recipe for MSgg is as follows: $5 \mathrm{mM}$ potassium phosphate ( $\mathrm{pH} 7.0$ ), $100 \mathrm{mM}$ MOPS (morpholine propane sulfonic acid) ( $\mathrm{pH} 7.0$ ), $2 \mathrm{mM} \mathrm{MgCl}, 700 \mu \mathrm{M} \mathrm{CaCl}_{2}, 50 \mu \mathrm{M} \mathrm{MnCl}, 50 \mu \mathrm{M} \mathrm{FeCl} \mathrm{Me}_{3}$, $1 \mu \mathrm{M} \mathrm{ZnCl}, 2 \mu \mathrm{M}$ thiamine, $0.5 \%$ glycerol, $0.5 \%$ glutamic acid, $50 \mu \mathrm{g} / \mathrm{mL}$ tryptophan, $50 \mu \mathrm{g} / \mathrm{mL}$ threonine, and $50 \mu \mathrm{g} / \mathrm{mL}$ phenylalanine (Branda et al., 2001). Escherichia coli DH5 $\alpha$ was used as a host for molecular cloning and grown at $37^{\circ} \mathrm{C}$ in $\mathrm{LB}$ medium. A. citrulli $\mathrm{MH} 21$ was grown at $28^{\circ} \mathrm{C}$ in $\mathrm{LB}$ medium (Ren et al., 2014). When required, antibiotics were added at the following concentrations for growth of B. subtilis: $5 \mu \mathrm{g} / \mathrm{mL}$ of chloramphenicol, $10 \mu \mathrm{g} / \mathrm{mL}$ of tetracycline. For growth of E. coli and $A$. citrulli $\mathrm{MH} 21$, antibiotics were added at the following concentrations: $100 \mu \mathrm{g} / \mathrm{mL}$ of ampicillin and $50 \mu \mathrm{g} / \mathrm{mL}$ of ampicillin, respectively.

\section{DNA Manipulations}

The general methods for molecular cloning were performed according to standard procedures (Sambrook and Russell, 2001). Restriction enzymes and other enzymes for molecular cloning were all purchased from Takara Co., Ltd. (Dalian, China). PCR products were purified with a PCR purification kit (Tiangen Biotech Co., Ltd., Beijing, China) and used according to the manufacturer's instructions. The plasmids were isolated using a plasmid mini-prep kit purchased from Bioteke 
Bio Solutions Co., Ltd. (Beijing, China). E. coli DH5 $\alpha$ cells were transformed by heat shock transformation. B. subtilis cells were transformed by electroporation using a Gene-Pulser (Bio-Rad, MicroPulser, United States), as recommended by the manufacturer. Oligonucleotide primer synthesis and DNA sequencing services were performed at Tsingke Biological Technology Co., Ltd. (Beijing, China).

\section{Antibacterial Activity Assay and Minimum Inhibitory Concentration Determination}

The antagonistic activity of B. subtilis 9407 against $A$. citrulli MH21 was roughly analyzed as previously described (Wu et al., 2015), with some modifications. Fresh A. citrulli MH21 plates were prepared for the assay. When the concentration of $A$. citrulli $\mathrm{MH} 21$ grown in $\mathrm{LB}$ medium at $28^{\circ} \mathrm{C}$ was up to $4 \times 10^{7} \mathrm{CFU} / \mathrm{mL}$, $5 \mathrm{~mL}$ bacteria suspension was mixed with $300 \mathrm{~mL}$ melting LB agar and cooled below $60^{\circ} \mathrm{C}$ to prepare the plates. The $1 \mu \mathrm{L}$ of an overnight culture of $B$. subtilis 9407 was spotted onto the surface of the plate which was then incubated at $28^{\circ} \mathrm{C}$ for $48 \mathrm{~h}$ to observe the growth inhibition effect. The diameters of inhibition zones were then measured and recorded. The other plant pathogens tested in this study were supplied by the Department of Plant Pathology in the College of Plant Protection at China Agricultural University, China.

To analyze the antibacterial activity of the extraction of lipopeptides from B. subtilis 9407, $10 \mu \mathrm{L}$ of the appropriate dilutions of lipopeptide crude extracts were loaded into wells punched in $A$. citrulli $\mathrm{MH} 21$ plates prepared by the method described above. The plates were incubated at $28^{\circ} \mathrm{C}$ for $48 \mathrm{~h}$ and the antibacterial abilities of the lipopeptide crude extracts were assessed by observing the resulting inhibition zones.

The inhibiting activity of $\triangle s r f A B$ and $\triangle p p s B$ against $A$. citrulli MH21 was also tested by spotting bacterium on $A$. citrulli $\mathrm{MH} 21$ plates prepared by the method described above. B. subtilis 9407 used as a control was also spotted. Then the plates were incubated at $28^{\circ} \mathrm{C}$ for $48 \mathrm{~h}$ to observe the growth inhibition effect.

The inhibiting activity of the extraction of lipopeptides from wild-type strain 9407, $\triangle s r f A B$ and $\triangle p p s B$ were also tested by spotting $10 \mu \mathrm{L}$ of lipopeptide crude extracts into wells punched in A. citrulli MH21 plates according to the method described above.

The minimum inhibitory concentration (MIC) of lipopeptide crude extracts from $B$. subtilis 9407 against $A$. citrulli MH21 was determined as previously described (Bais et al., 2004). In brief, A. citrulli MH21 was first grown in $5 \mathrm{~mL} \mathrm{LB}$ broth to $4 \times 10^{5}$ $\mathrm{CFU} / \mathrm{mL}$, and $190 \mu \mathrm{L}$ of culture was added to 96 -well microtiter plates. Then, $10 \mathrm{~mL}$ of serial 2-fold dilutions of lipopeptide crude extracts was mixed with culture in 96-well plates. Ten microliters of the methanol was used as control. The MIC was visually defined as the lowest concentration of an antibiotic that completely inhibited cell growth after incubation for $24 \mathrm{~h}$ at $28^{\circ} \mathrm{C}$. All susceptibility trials were conducted in triplicate.

The MIC of surfactin standard for A. citrulli MH21 was determined according to the method described above. Four microliters of the serial 2-fold dilutions of commercial surfactin was mixed with $196 \mathrm{~mL}$ of $A$. citrulli MH21 culture in 96-well plates. Commercial surfactin (Sigma-Aldrich, St. Louis, MO, United States) was dissolved in dimethyl sulfoxide (DMSO). Four microliters of the DMSO was used as control.

\section{Construction of srfAB Marked Deletion Mutant in B. subtilis 9407}

The $\operatorname{srf} A B$ marked deletion mutant was constructed using the temperature-sensitive suicide plasmid pMAD as described previously (Arnaud et al., 2004). A tetracycline resistance gene (Tet) was amplified by polymerase chain reaction (PCR) from plasmid pGFP78 (Gao et al., 2015) using primer pair Tet-F and Tet-R (All primer sequences are shown in Supplementary Table S2). The resulting fragment was digested with SpeI/PstI and cloned into pEBS (Wang et al., 2007), which had also been digested with SpeI/PstI, generating pEBST. Regions that were upstream and downstream of the $\operatorname{sr} A B$ gene were amplified from B. subtilis 9407 genomic DNA using the primer pairs srfABUp-F/srfAB-Up-R and srfAB-Dn-F/srfAB-Dn-R, respectively. These fragments were digested with SalI/PstI and SpeI/SacI, respectively, and were cloned into the pEBST plasmid to create pEBST-srfAB. The Up-Tet-Dn fragment was amplified from pEBST-srfAB using the primer pair srfAB-F and srfAB-R. The resulting fragment was digested with $B g l \mathrm{II} / M l u \mathrm{I}$ and cloned into pMAD, which had also been digested with $B g l \mathrm{II} / M l u \mathrm{I}$, generating pMAD-srfAB. The pMAD-srfAB plasmid was subsequently mobilized into B. subtilis 9407 by electroporation. Transformants were obtained after incubation at $30^{\circ} \mathrm{C}$ for 2 days on $\mathrm{LB}$ plates containing erythromycin and X-Gal $(40 \mu \mathrm{g} / \mathrm{mL})$. The allelic replacement of pMAD-srfAB in B. subtilis 9407 was performed according to the published protocol (Arnaud et al., 2004). Erythromycin-sensitive clones were isolated, and the mutants were identified by PCR with primer pair srfAB-F and srfAB-R and subsequently confirmed by Sanger sequencing.

\section{Extraction of Lipopeptides}

Lipopeptide extraction was performed as previously described (Chen et al., 2016). In brief, after cultivating the cells in $50 \mathrm{~mL}$ Landy medium at $30^{\circ} \mathrm{C}$ for $72 \mathrm{~h}$, the cell-free supernatant was obtained by centrifugation at $6,000 \times g$ for $10 \mathrm{~min}$ and filtration using a bacterial filter $(\varphi=0.22 \mu \mathrm{m})$. The column (Sigma Amberlite) containing $6 \mathrm{~g}$ of XAD16 adsorbent resin (Sigma-Aldrich, St. Louis, MO, United States) was washed with $50 \mathrm{~mL}$ of deionized water to remove salts. The cellfree supernatant was passed through the XAD16 resin column, washed with deionized water and eluted with $14 \mathrm{~mL}$ of $100 \%$ methanol. The lipopeptide crude extracts were dissolved in $1 \mathrm{~mL}$ of methanol, followed by drying with a rotary evaporator.

\section{Semipreparative Reverse-Phase High Performance Liquid Chromatography (RP-HPLC)}

The samples were run on an RP-HPLC equipped with Waters Sunfire C18 columns $(5 \mu \mathrm{m}, 4.6 \times 150 \mathrm{~mm})$ at room temperature, with a flow rate of $1.0 \mathrm{~mL} / \mathrm{min}$. The mobile phase consisted of $0.1 \%$ trifluoroacetic acid (TFA) in HPLC grade water (solvent A) 
and $0.1 \%$ TFA in HPLC grade acetonitrile (solvent B). The elution was monitored by determining the absorbance at $214 \mathrm{~nm}$. Commercial surfactin (Sigma-Aldrich, St. Louis, MO, United States) was used as standards.

\section{Liquid Chromatography Electrospray Ionization Tandem Mass Spectrometry (LC-MS/MS) Analysis}

Quattro Premier XE tandem quadrupole mass spectrometer (Waters) was used for LC-MS/MS analysis. The Waters Sunfire C18 column $(4.6 \times 150 \mathrm{~mm}, 5 \mu \mathrm{m})$ was used for liquid chromatography at $1.0 \mathrm{~mL} / \mathrm{min}$ flow rate, at $25^{\circ} \mathrm{C}$. The mobile phase consisted of solvent A and solvent B. Solvent A was water, eluent $\mathrm{B}$ was acetonitrile (ACN), both containing $0.1 \%$ formic acid (FA). The injection volume was $10 \mu \mathrm{L}$ of surfactin standard (1 mg/mL) or lipopeptide crude extracts from B. subtilis 9407. The elution was monitored by determining the absorbance at $214 \mathrm{~nm}$. The mass spectral was analyzed in both the negative ion and positive ion mode (ESI+/ESI-), the other parameters were as follows: $120^{\circ} \mathrm{C}$ source temperature; voltages were $3.2 \mathrm{kV}$ for the capillary and $30 \mathrm{~V}$ for the cone voltage, $350^{\circ} \mathrm{C}$ desolvation temperature. Surfactin standard was purchased from Surfactin (Sigma-Aldrich, St. Louis, MO, United States).

\section{Analysis of Biofilm Formation}

The biofilm formation was analyzed in MSgg medium by using the method described previously (Yan et al., 2016). The wild-type and $\triangle s r f A B$ strains were first grown in $5 \mathrm{~mL} \mathrm{LB}$ broth to late exponential growth phase $\left(\mathrm{OD}_{600}=1.0\right)$, and $4 \mu \mathrm{L}$ of culture was added to $4 \mathrm{~mL}$ of MSgg medium (a 1000-fold dilution) in 12-well St. microtiter plates and incubated statically at $25^{\circ} \mathrm{C}$ for $72 \mathrm{~h}$.

In the experiments for the restoration of biofilm formation, $2 \mu \mathrm{L}$ of the appropriate dilutions of commercial surfactin was mixed with $4 \mathrm{~mL}$ of MSgg medium in 12-well plates prior to inoculation with $\triangle s r f A B$. Commercial surfactin (Sigma-Aldrich, St. Louis, MO, United States) was dissolved in DMSO.

\section{Assays of Swarming Motility}

Swarming motility assays of wild-type B. subtilis 9407 and $\triangle \operatorname{srfAB}$ were performed according to Chen et al. (2012). In brief, $5 \mathrm{~mL}$ LB liquid cultures were prepared with shaking $(200 \mathrm{rpm})$ at $37^{\circ} \mathrm{C}$ to mid-log phase, $1 \mathrm{~mL}$ of cells were collected by centrifugation at $6,000 \times g$ for $5 \mathrm{~min}$, washed with phosphate-buffered saline (PBS; $137 \mathrm{mM} \mathrm{NaCl}, 2.7 \mathrm{mM} \mathrm{KCl}, 10 \mathrm{mM} \mathrm{Na}_{2} \mathrm{HPO}_{4}$, and $2 \mathrm{mM}$ $\mathrm{KH}_{2} \mathrm{PO}_{4}$ ), and resuspended in $100 \mu \mathrm{L}$ PBS. The swarming agar plates (LB solidified with $0.7 \%$ agar) were dried for $20 \mathrm{~min}$ in a laminar flow hood, centrally inoculated with $3 \mu \mathrm{L}$ of the cell suspension, dried for another $10 \mathrm{~min}$ and incubated at $30^{\circ} \mathrm{C}$ for 6.5-7 h (the surface of the plates inoculated with wild-type cells had almost been fully covered by the swarming cells). Afterward, the swarming plates were removed to a laminar flow hood, dried for $1 \mathrm{~h}$ and incubated at room temperature for another $12 \mathrm{~h}$ to allow cell growth in order to clearly visualize the swarming zone. The diameter of the swarming zone was measured.

For extracellular complementation experiments, $2 \mu \mathrm{L}$ of the appropriate dilutions of commercial surfactin (dissolved in
DMSO) was spotted at the center of swarming agar plates and dried in a laminar flow hood before the motility assay.

\section{Colonization Assay}

$B$. subtilis 9407 and $\triangle s r f A B$ strains were marked with resistance gene using the shuttle vector $\mathrm{pC}-1$ containing a chloramphenicol resistance gene. The plasmid $\mathrm{pC}-1$ was transformed into B. subtilis 9407 and $\triangle s r f A B$ by electroporation. Transformants were selected with chloramphenicol and then identified by PCR with primer pair $\mathrm{pC}-1-\mathrm{F}$ and $\mathrm{pC}-1-\mathrm{R}$.

The melon (Cucumis melo) was used for colonization assays. Melon seeds were soaked in the $55^{\circ} \mathrm{C}$ water for $30 \mathrm{~min}$, placed between the wet gauze, and incubated at $28^{\circ} \mathrm{C}$ for $36 \mathrm{~h}$ to germinate. The wild-type and $\triangle \operatorname{srf} A B$ strains were grown in nutrient broth $(\mathrm{NB})$ in a shaker at $30^{\circ} \mathrm{C}$ with $160 \mathrm{rpm}$ for $48 \mathrm{~h}$. The cells were harvested by centrifugation at $6,000 \times g$ for $10 \mathrm{~min}$ and adjusted with PBS buffer ( $\mathrm{pH} \mathrm{7.0)}$ to obtain the desired bacterial concentration $\left(10^{7} \mathrm{CFU} / \mathrm{mL}\right)$. The germinated melon seeds were soaked in the bacterial suspension at room temperature for $30 \mathrm{~min}$ with gentle agitation. Seeds soaked in PBS buffer alone were used as the controls. After that the treated seeds were air-dried and sown in $600 \mathrm{~mL}$ black plastic pots ( ix seeds per pot) filled with sterile soil and vermiculite in a ratio of $2: 1$. Three pots were used for each replicate and three replicates were used for each bacterial strain. The pots were placed in a growth chamber at $28^{\circ} \mathrm{C}$ with a $16 \mathrm{~h}$ photoperiod and $60 \%$ humidity. Samples were collected at $0,5,10,15$, and 20 days post inoculation. To assays of cell colonization on roots and leaves, $0.1 \mathrm{~g}$ fresh weight of the melon roots and leaves were collected. Samples were surface sterilized by $3 \mathrm{~min}$ in sodium hypochloride (10\% active chlorine) and washed three times with sterile water for at least $5 \mathrm{~min}$ each. The surfacesterilized samples were then disrupted in a sterile mortar and pestle. The suspensions were diluted by 10 -fold serial dilutions in sterile water, and $100 \mu \mathrm{L}$ of each diluted suspension was plated on LB agar plates supplemented with chloramphenicol $(5 \mu \mathrm{g} / \mathrm{mL})$ and then incubated at $37^{\circ} \mathrm{C}$ for $12 \mathrm{~h}$. Bacterial colony-forming units on each plate were counted. The experiments were repeated three times.

\section{Biocontrol of Bacterial Fruit Blotch under Greenhouse Conditions}

Melon was used to evaluate the biocontrol activity of wildtype strain 9407 and $\triangle s r f A B$ against $A$. citrulli MH21. Melon seeds were pre-germinated as described above. The bacterial suspensions of $B$. subtilis 9407 and $\triangle s r f A B$ were prepared by the method described in Section "Colonization Assay." The germinated seeds were soaked in the bacterial suspension at room temperature for $30 \mathrm{~min}$ with gentle agitation and then air-dried. Seeds soaked in PBS buffer alone were used as the controls. Eight treated seeds were sown in $600 \mathrm{~mL}$ black plastic pots filled with soil and vermiculite in a ratio of 2:1. The pots were placed in a greenhouse with the following conditions: $28-30^{\circ} \mathrm{C}, 60 \%$ humidity, and $16 \mathrm{~h}$ of light alternating with $8 \mathrm{~h}$ of darkness. A. citrulli $\mathrm{MH} 21$ was cultured at $28^{\circ} \mathrm{C}$ for $48 \mathrm{~h}$ in $\mathrm{LB}$ broth. The cells were harvested by centrifugation at $5,000 \times g$ for $15 \mathrm{~min}$ and 


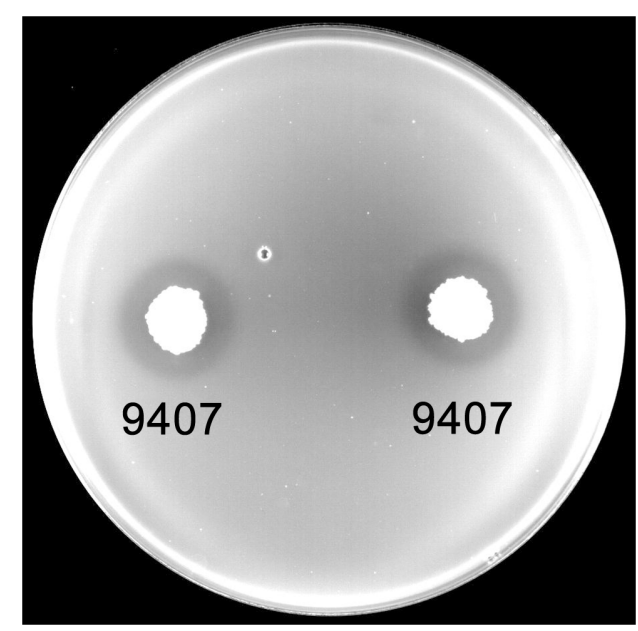

FIGURE 1| The antagonistic activity of $B$. subtilis 9407 against $A$. citrulli in a dual culture test on a LB plate.

the bacterial suspension was adjusted with PBS to $10^{8} \mathrm{CFU} / \mathrm{mL}$. After sown for 3 days, both sides of the leaves were sprayed with bacterial suspension of $A$. citrulli $\mathrm{MH} 21$.

The seedlings were evaluated for BFB severity daily based on the disease index, as described previously (Bahar et al., 2009). The disease index of each leaf was rated using a scale of 0-6, where 0 , no symptom; $1,10 \%$ or less necrotic lesions on the leaves; $2-5,11-25 \% ; 26-50 \% ; 51-75 \%$ and $76-90 \%$ necrotic lesions on the leaves, respectively; and $6,>90 \%$ necrosis of the leaves. The disease severity and biocontrol efficacy were calculated as follows:

Disease severity $(\%)=\Sigma$ the number of diseased leaves in each grade $\times$ grade/(total number of leaves investigated $\times$ the highest disease index $) \times 100$.

Biocontrol efficacy $(\%)=$ (incidence rate in the control incidence rate in the Bacillus-treated group)/ incidence rate in the control $\times 100$.

Three pots were used for each replicate, and the values were recorded as the means of three replicates for each treatment. The experiments were repeated three times.

\section{Statistical Analysis}

The data were statistically analyzed using SPSS software 20.0. Student's $t$-tests were used to determine the significant differences.

\section{RESULTS}

\section{B. subtilis 9407 Showed Strong Antibacterial Activity against $A$. citrulli}

To investigate the antibacterial activity of B. subtilis 9407 against $A$. citrulli $\mathrm{MH} 21$, a dual culture assay was conducted. Two days after inoculation, the inhibition zone of $B$. subtilis 9407 was $18.1 \mathrm{~mm}$, suggesting that B. subtilis 9407 could observably inhibit the growth of A. citrulli MH21 (Figure 1).
TABLE 1 | Antibacterial activity of B. subtilis 9407 determined in agar diffusion test.
Indicator strains

Pseudomonas syringae pv.

tomato DC3000

Xanthomonas campestris pv.

campestris Xcc 8004

Pectobacterium carotovora

subsp. carotovora Ecc 09

Clavibacter michiganensis

subsp. michiganensis BT0505

Pectobacterium atrosepticum

SCRI1043

Acidovorax citrulli $\mathrm{MH} 21$
Diameter of the inhibition zone (mm)

18.0

10.2

10.8

0

15.8

18.3
Moreover, B. subtilis 9407 showed significant antagonistic activity in vitro toward other pathogens that cause plant diseases in tomato, oilseed rape, Chinese cabbage, potato and other plants (Table 1).

\section{B. subtilis 9407 Exhibited High Biocontrol Efficacy on Bacterial Fruit Blotch}

Next, we evaluated the biocontrol ability of B. subtilis 9407 against $\mathrm{BFB}$ caused by $A$. citrulli $\mathrm{MH} 21$ on melon under greenhouse conditions. We performed biocontrol assays using the B. subtilis 9407 strain pretreated seeds and inoculated A. citrulli MH21 3 days after planted (see "Materials and Methods"). Four days after $A$. citrulli MH21 inoculation, the disease severity of melon seedlings that were pre-treated with PBS (control) was $43.52 \%$ (Table 2). The disease severity of melon seedlings that were pre-treated with B. subtilis 9407 was $16.67 \%$, for a noticeable reduction compared with the PBS treated control. Accordingly, the efficacy of B. subtilis 9407 in controlling the BFB caused by $A$. citrulli $\mathrm{MH} 21$ up reached $61.7 \%$. Seven days post inoculation, the biocontrol efficacy of B. subtilis 9407 against BFB was $57.8 \%$ (Table 2). These results indicated that B. subtilis 9407 is a potential biological control agent for efficiently controlling BFB.

TABLE 2 | Biocontrol assay of B. subtilis 9407 against bacteria fruit blotch under greenhouse condition.

\begin{tabular}{|c|c|c|c|c|}
\hline \multirow[t]{2}{*}{ Treatment } & \multicolumn{2}{|c|}{4 days post inoculation } & \multicolumn{2}{|c|}{7 days post inoculation } \\
\hline & $\begin{array}{c}\text { Disease } \\
\text { severity (\%) }\end{array}$ & $\begin{array}{l}\text { Biocontrol } \\
\text { efficacy (\%) }\end{array}$ & $\begin{array}{c}\text { Disease } \\
\text { severity (\%) }\end{array}$ & $\begin{array}{l}\text { Biocontrol } \\
\text { efficacy (\%) }\end{array}$ \\
\hline B. subtilis 9407 & $16.67 \pm 2.38^{a}$ & 61.7 & $27.78 \pm 2.78^{a}$ & 57.8 \\
\hline Control & $43.52 \pm 5.26^{b}$ & - & $65.87 \pm 8.36^{b}$ & - \\
\hline
\end{tabular}

The germinated melon seeds were soaked in bacterial suspensions of B. subtilis 9407 at $10^{7} \mathrm{CFU} / \mathrm{mL}$ for $30 \mathrm{~min}$. Phosphate-buffered saline (PBS) was used as control. After sown for 3 days, both sides of the melon leaves were sprayed with bacterial suspension of $A$. citrulli $\mathrm{MH} 21\left(10^{8} \mathrm{CFU} / \mathrm{mL}\right.$ ). Three pots (eight seeds per pot) were used for each replicate. Data are presented as means of three replicates $\pm S D$, and error bars represent $S D$ for three replicates. Means with different letters have significant differences $(P<0.01)$. 


\section{Lipopeptide Crude Extracts from B. subtilis 9407 Showed Strong Antibacterial Activity against $A$. citrulli MH21}

To identify the primary antibacterial compound of $B$. subtilis 9407 against $A$. citrulli, the antibacterial activity of lipopeptide crude extracts from B. subtilis 9407 was tested against $A$. citrulli MH21 as described in Section "Materials and Methods." Lipopeptide crude extracts from B. subtilis 9407 showed antibacterial activity against $A$. citrulli $\mathrm{MH} 21$, at the dilution rate from 0 - to 10-fold (Figure 2). The MIC of lipopeptide crude extracts from B. subtilis 9407 for A. citrulli MH21 was determined to be 40 times dilution of lipopeptide crude extracts. These results indicated that lipopeptide crude extracts from B. subtilis 9407 showed strong antibacterial activity against A. citrulli MH21.

\section{The $\triangle$ srfAB Mutant Showed No Ability to Inhibit Growth of $A$. citrulli MH21}

To further identify the primary antibacterial compound of $B$. subtilis 9407 against $A$. citrulli, we decided to mutate candidate genes for biosynthesis of selected lipopeptide, which were reported to show antibacterial activity. The selected candidate genes were $s r f A B$ and $p p s B$, responsible for the synthesis of surfactin and fengycin, respectively (Zeriouh et al., 2014; Fan et al., 2017). To generate a $\operatorname{srfAB}$ marked deletion mutant, the temperature-sensitive suicide plasmid pMADsrfAB was constructed (see "Materials and Methods") to disrupt the open reading frame of the $\operatorname{srf} A B$ gene, abrogating the production of surfactin. The surfactin synthesis abilities of the wild-type B. subtilis 9407 and $\triangle \operatorname{srfAB}$ were further detected by RP-HPLC (Figure 3). It was found that wild-type B. subtilis 9407 produced surfactin, while $\triangle \operatorname{srfAB}$ completely

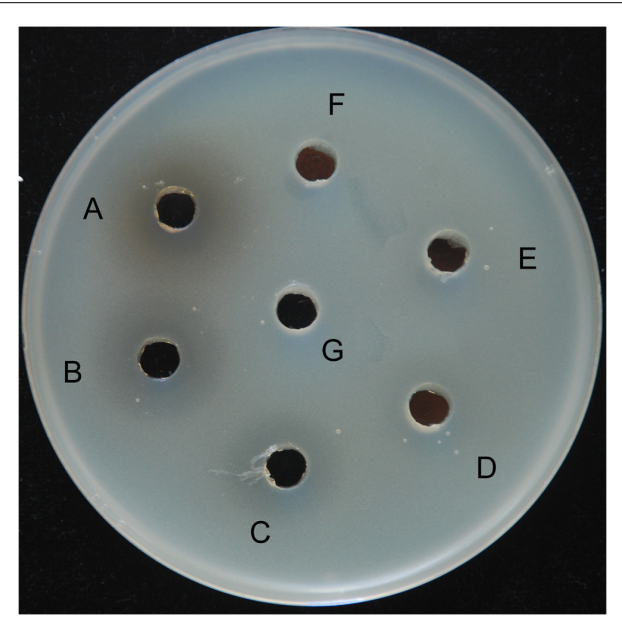

FIGURE 2 | An antagonistic assay against $A$. citrulli in vitro by lipopeptide crude extracts from B. subtilis 9407. (A) lipopeptide crude extracts, (B) 2-fold dilution of lipopeptide crude extracts, (C) 5 -fold dilution of lipopeptide crude extracts, (D) 10-fold dilution of lipopeptide crude extracts, (E) 50-fold dilution of lipopeptide crude extracts, (F) 100-fold dilution of lipopeptide crude extracts and (G) methanol.

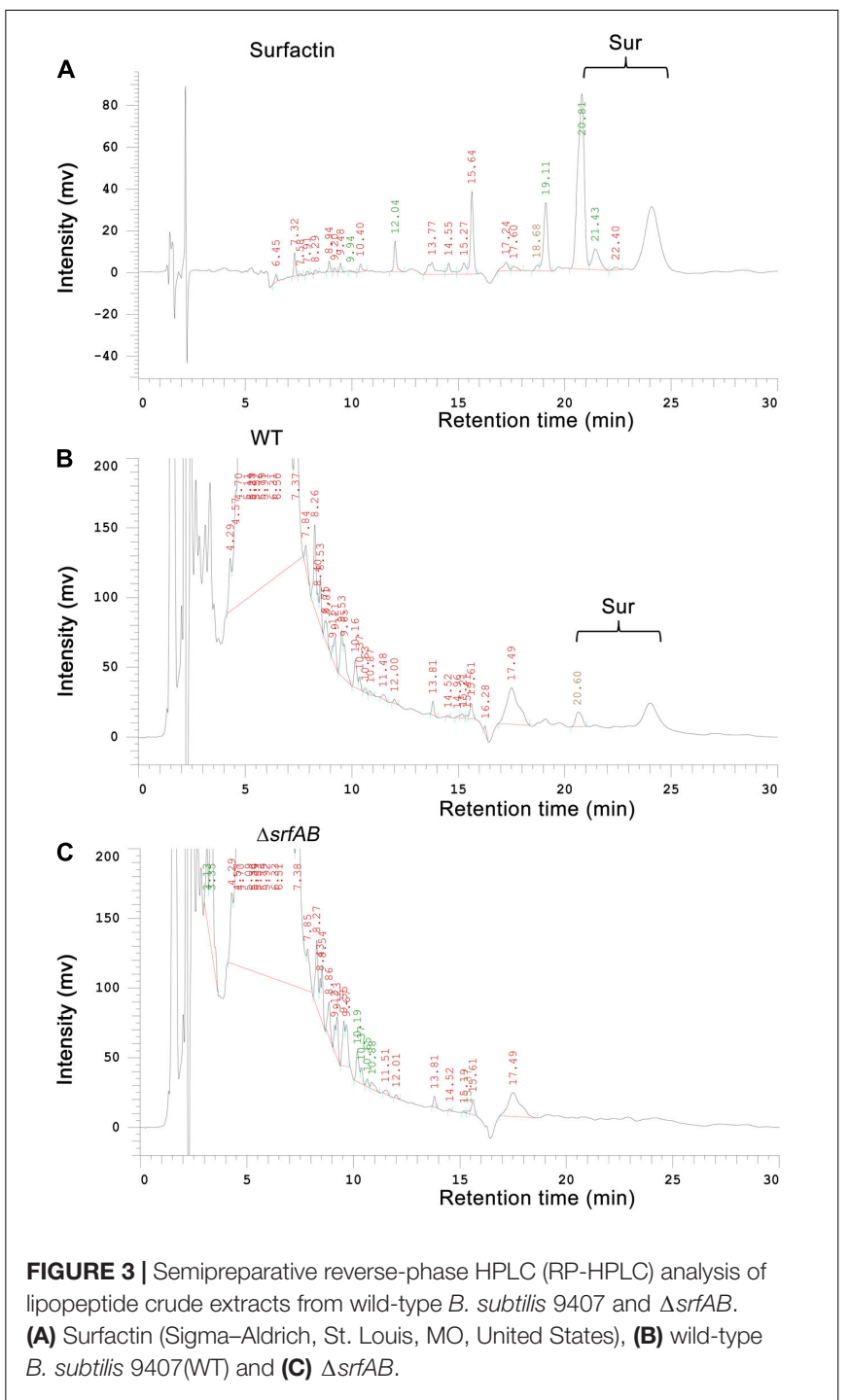

lost the ability to produce surfactin. In our previous work, we confirmed that the $\triangle p p s B$ was phenotypically characterized as non-fengycin producer (Fan et al., 2017). We tested the antibacterial activity of the mutants against $A$. citrulli MH21. Compared with the wild-type B. subtilis 9407, $\triangle p p s B$ showed a reduced antibacterial activity against $A$. citrulli $\mathrm{MH} 21$. However, $\triangle \operatorname{srf} A B$ showed no clear zone of inhibition of the growth of $A$. citrulli MH21 (Figure 4). After that, lipopeptide crude extracts were subjected to analyze the antibacterial activity in vitro. Consistent with our hypothesis, lipopeptide crude extracts from $\triangle \operatorname{srf} A B$ showed almost no inhibition of $A$. citrulli $\mathrm{MH} 21$ (Figure 5). These results suggested that surfactin is the primary active compound to exert the inhibitory effect of B. subtilis 9407 against $A$. citrulli MH21.

To further characterize surfactin produced by $B$. subtilis 9407, the complete surfactin gene cluster of B. subtilis 9407 was aligned with that in B. subtilis subsp. subtilis str. 168, B. subtilis subsp. subtilis 6051-HG and B. subtilis SG6, which were 


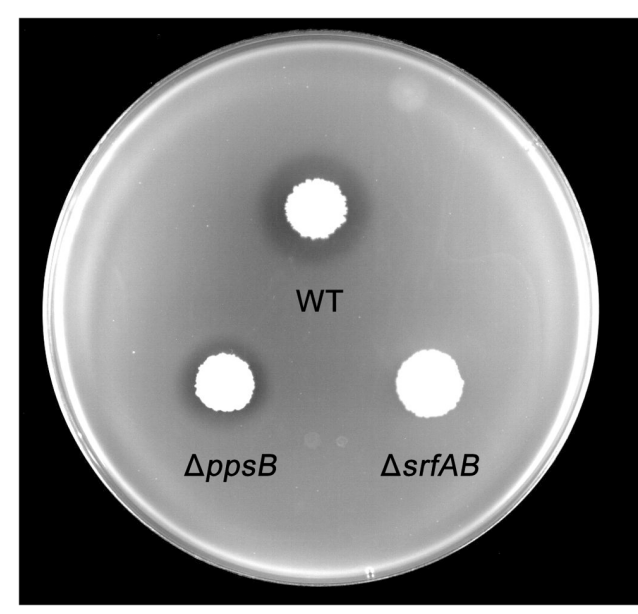

FIGURE 4 | Antibacterial activity assay of $B$. subtilis 9407(WT), $\Delta p p s B$ and $\triangle$ sifAB against $A$. citrulli on a LB plate.

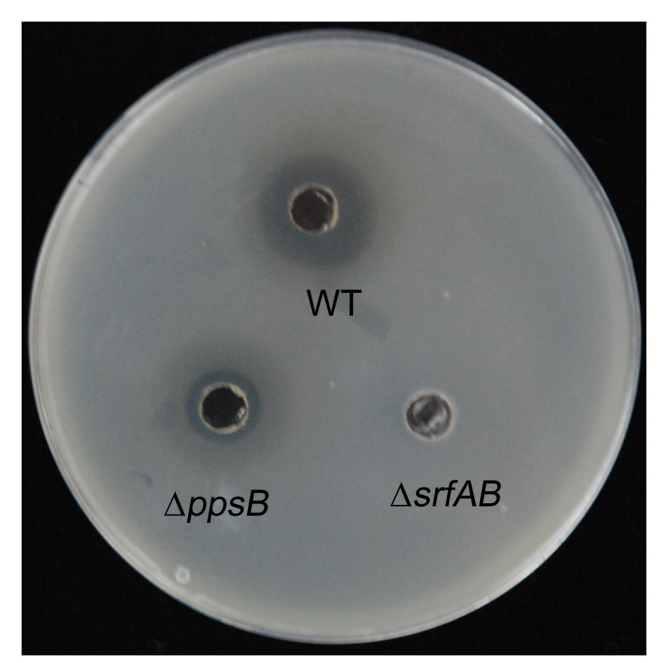

FIGURE 5 | An antagonistic assay against $A$. citrulli in vitro by lipopeptide crude extracts from $B$. subtilis $9407(\mathrm{WT}), \Delta p p s B$ and $\triangle$ sifAB.

reported to produced surfactin A (Aleti et al., 2015, 2016). It was found that the complete surfactin gene cluster of B. subtilis 9407 displays $98.99 \%$ sequence identity to B. subtilis subsp. subtilis str. 168 and B. subtilis subsp. subtilis 6051-HG and $98.57 \%$ to $B$. subtilis SG6. AntiSMASH analysis of the surfactin cluster of B. subtilis 9407 predicted a lipopeptide sequence of L-Glu-L-Leu-D-Leu-L-Val-L-Asp-D-Leu-L-Ile, namely surfacrin A (Figure 6). Moreover, lipopeptide crude extracts from B. subtilis 9407 and commercial standard for surfactin, which is composed of a macrolide containing the heptapeptide Glu-Leu-Leu-Val-Asp-Leu-Leu (Lim et al., 2005; Aleti et al., 2016) were subjected to LC-MS/MS analysis. The LC-MS/MS analysis of B. subtilis 9407 lipopeptide crude extracts showed a series of four peaks with identical mass to surfactin standard (Figure 7). For each of the four compounds, the

\begin{tabular}{|c|c|c|c|c|}
\hline \multicolumn{2}{|l|}{ srfAA } & $s r f A B$ & sifAC & srfAD \\
\hline 曲 & 曲 & 监口册 & III⿴囗口曲 & 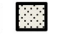 \\
\hline Leu & Leu & Asp & Leu & \\
\hline |⿴囗⿰丿㇄口 & & 曲 & 2 & \\
\hline $\begin{array}{l}\text { Condensation } \\
\text { domain }\end{array}$ & $\begin{array}{c}\text { Adenylation } \\
\text { domain }\end{array}$ & $\begin{array}{l}\text { Thiolation } \\
\text { domain }\end{array}$ & $\begin{array}{c}\text { Thioesteras } \\
\text { domain }\end{array}$ & \\
\hline $\begin{array}{l}\text { FIGURE } 6 \text { | Dom } \\
\text { B. subtilis } 9407 . \\
\text { adenylation doma }\end{array}$ & $\begin{array}{l}\text { n organization of } \\
\text { e amino acids rec } \\
\text { are listed under } t\end{array}$ & $\begin{array}{l}\text { רthetase gene c } \\
\text { ited for the lipo } \\
\text { domain organi }\end{array}$ & $\begin{array}{l}\text { ding for surfac } \\
\text { aptide by each } \\
\text { ation. }\end{array}$ & tin in \\
\hline
\end{tabular}

LC-MS/MS spectra with the same precursor $\mathrm{m} / \mathrm{z}$ exhibited the quite similar fragmentation behavior was observed in the surfactin standard (Figure 8). These results indicated that the surfactin produced by B. subtilis 9407 is a mixture of C13- to C16-surfactin A.

In order to determine the antibacterial activity of surfacrin, the MIC of surfactin standard was tested. It was found that the MIC of surfactin standard against A. citrulli MH21 was $100 \mu \mathrm{g} / \mathrm{mL}$. Surfactin standard also showed antibacterial activity against $A$. citrulli $\mathrm{MH} 21$ on LB agar (Figure 9). These results suggested that surfactin standard has antibacterial activity against A. citrulli $\mathrm{MH} 21$.

\section{The $\triangle$ srfAB Mutant Showed a Defect in Biofilm Formation}

Previous works have shown that surfactin triggers biofilm formation in B. subtilis (Romero, 2013; Zeriouh et al., 2014; Luo et al., 2015). We therefore asked whether this lipopeptide would also have a similar role in biofilm formation of $B$. subtilis 9407. We compared the biofilm formation phenotype of $\triangle \operatorname{srfAB}$ and wild-type. The results showed that wild-type $B$. subtilis 9407 formed wrinkly floating pellicles at the liquid-air interface of liquid cultures in MSgg (Figure 10). In contrast, the $\triangle \operatorname{srf} A B$ formed thinner pellicles in MSgg (Figure 10). Next, we tested whether the commercial surfactin could rescue the biofilm formation. We found that biofilm formation of $\triangle \operatorname{srf} A B$ was restored in the presence of exogenously supplemented surfactin at $10 \mu \mathrm{g} / \mathrm{mL}$ (Figure 10). Therefore, our evidence suggested that surfactin production is important for biofilm formation in B. subtilis 9407.

\section{The $\triangle$ srfAB Mutant Lacked Swarming Motility}

Swarming motility is an important mechanism for bacterial colonization and a type of bacterial social movement related to surfactin production (Kearns and Losick, 2003). To analyze swarming motility, cell suspension was spotted at the center of the swarming agar plates, and the diameter of the swarming zone was measured. The wild-type strain showed excellent swarming motility and the plate almost fully covered by the swarming cells. While, the $\triangle \operatorname{srf} A B$ showed a clear defect in swarming motility, with a $22.5 \mathrm{~mm}$ diameter of the swarming zone (Figures 11A,B). Based on the results of our external 
A

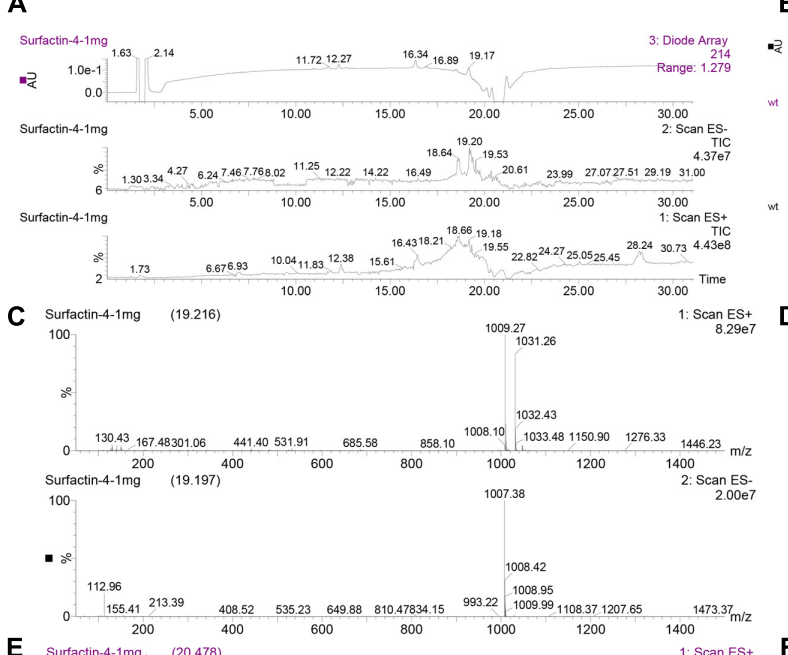

E

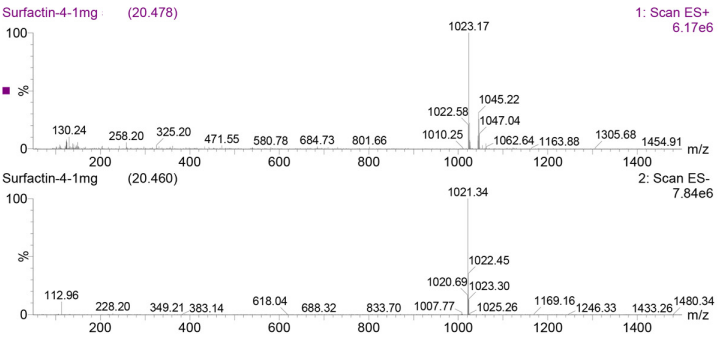

G
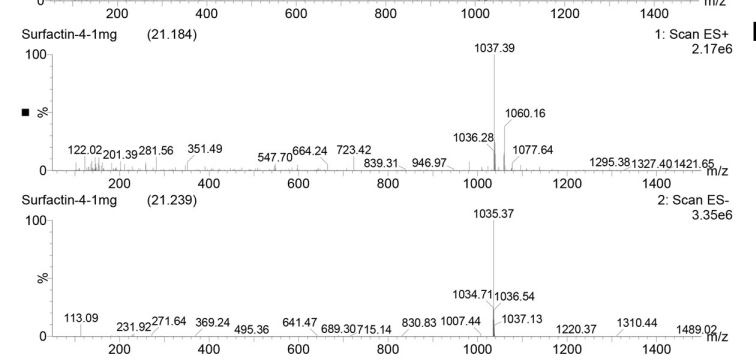

I

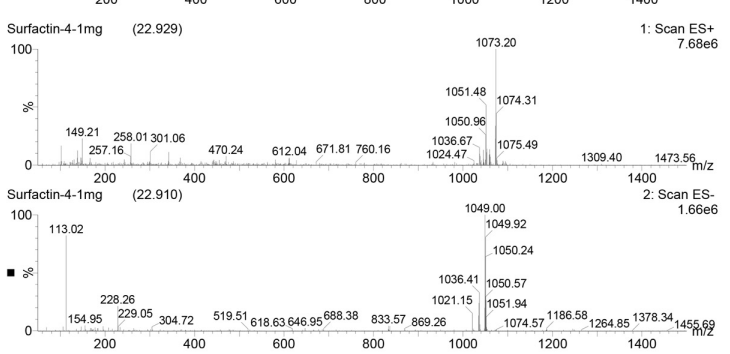

B
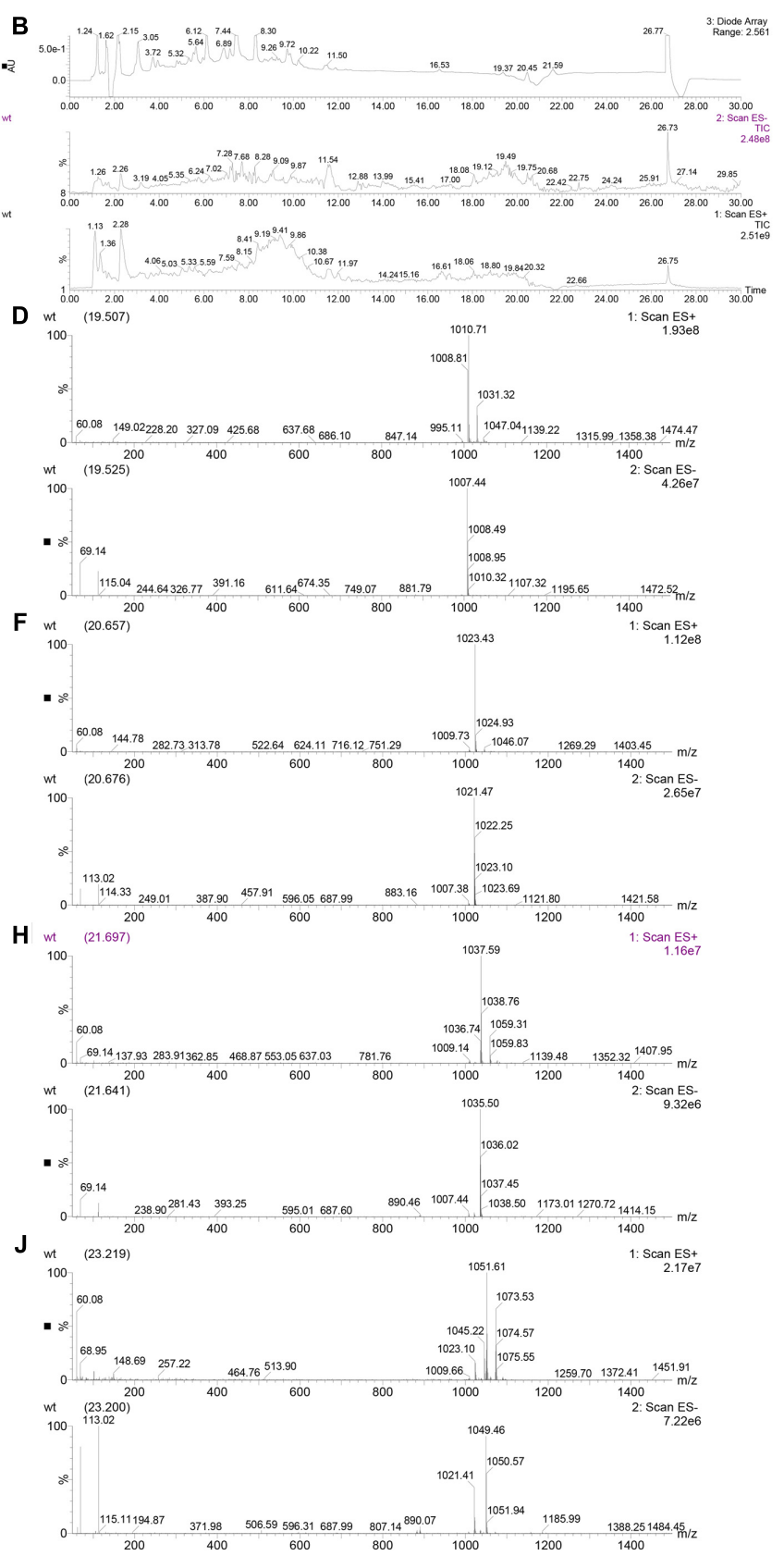

FIGURE 7 | Analysis of lipopeptide crude extracts from B. subtilis 9407 and commercial standard for surfactin by LC-MS/MS. (A) The UV chromatogram, total ion flow diagram for negative ion mode (ES-) and positive ion mode (ES+) of commercial surfactin standard. (B) The UV chromatogram, total ion flow diagram for ESand ES+ of lipopeptide crude extracts from B. subtilis 9407 . (C,E,G,I) The mass spectrums of surfactin standard with ES- and ES+. (D,F,H,J) The mass spectrums of lipopeptide crude extracts from B. subtilis 9407 with ES- and ES+.

complementation experiments, where commercial surfactin rescued biofilm formation (Figure 10), we decided to analyze the effect of surfactin in the restoration of swarming motility by $\triangle s r f A B$. It was found that $10 \mu \mathrm{g} / \mathrm{mL}$ of commercial surfactin was necessary to restore swarming motility of $\triangle \operatorname{srf} A B$ (Figures 11A,B). The above results indicated a significant role of the surfactin in swarming motility of $B$. subtilis 9407.

\section{Colonization Assay of Wild-type}

\section{$B$. subtilis 9407 and the $\triangle$ srfAB Mutant on Melon Leaves and Roots}

The implication of surfactin in the biofilm formation and swarming motility of $B$. subtilis suggested that this lipopeptide might have a role in the efficient colonization of melon leaves and roots. To test this hypothesis, the population dynamics of the 

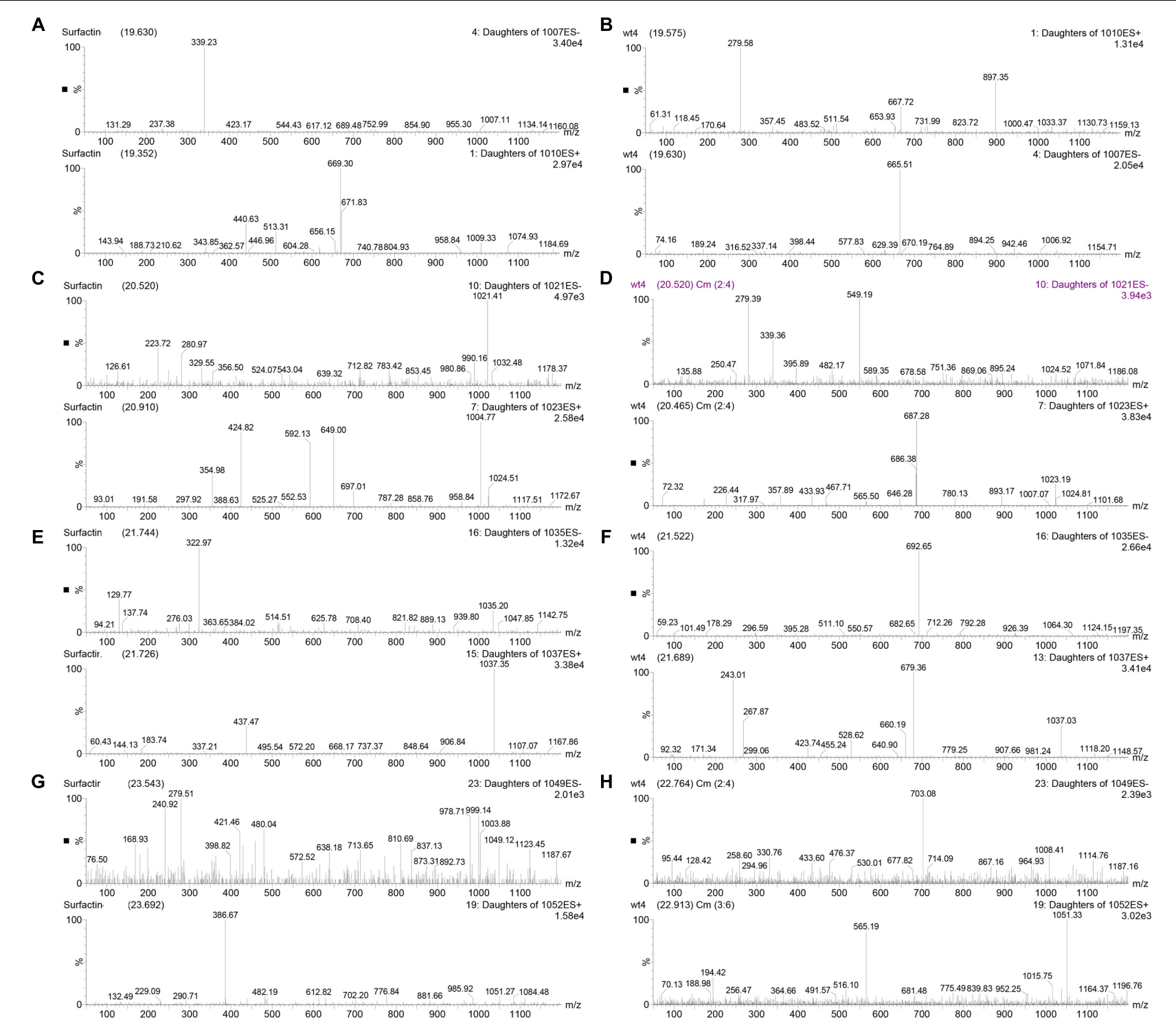

FIGURE 8 | LC-MS/MS analysis of lipopeptide crude extracts from B. subtilis 9407 and commercial standard for surfactin. (A,C,E,G) The MS/MS spectrums of surfactin standard with negative ion mode (ES-) and positive ion mode (ES+). (B,D,F,H) The MS/MS spectrums of lipopeptide crude extracts from B. subtilis 9407 with ES- and ES+.

wild-type and $\triangle \operatorname{srf} A B$ on melon leaves and roots were evaluated over time. The results showed that wild-type and $\triangle \operatorname{srf} A B$ could be isolated from the seedling tissues at $0,5,10,15$, and 20 days post inoculation, although the cell population of tested strains in the leaves and roots decreased continuously post inoculation (Tables 3, 4). The population of wild-type strain was higher in roots and leaves at each testing time point, where the highest level was reached at 5 days post inoculation, and the population was at a level of $3.56 \times 10^{4} \mathrm{CFU} / \mathrm{g}$ (fresh weight) in the leaves (Table 3) and $7.44 \times 10^{4} \mathrm{CFU} / \mathrm{g}$ (fresh weight) in the roots (Table 4). In contrast, the bacterial numbers of $\triangle \operatorname{srf} A B$ were significantly lower than wild-type strain, and at 5 days post inoculation, the population was $1.67 \times 10^{4} \mathrm{CFU} / \mathrm{g}$ (fresh weight) in the leaves (Table 3), $1.89 \times 10^{4} \mathrm{CFU} / \mathrm{g}$ (fresh weight) in the roots (Table 4). Similar results were obtained at 10, 15, 20 days post inoculation (Tables 3, 4). In comparison with the wild type, $\triangle \operatorname{srf} A B$ showed a two- to four-fold reduction and three- to ten-fold reduction in the number of leaves-colonizing cells and root-colonizing cells after inoculation, respectively. In general, the results strongly suggested that surfactin produced by B. subtilis 9407 affects the efficient colonization on melon leaves and roots.

\section{The $\triangle$ srfAB Mutant Was Defective in Its Biocontrol Activity}

To examine whether surfactin is responsible for the biocontrol of $B$. subtilis 9407 against BFB in vivo, the wild-type B. subtilis 9407 and $\triangle s r f A B$ were compared with the disease severity to 


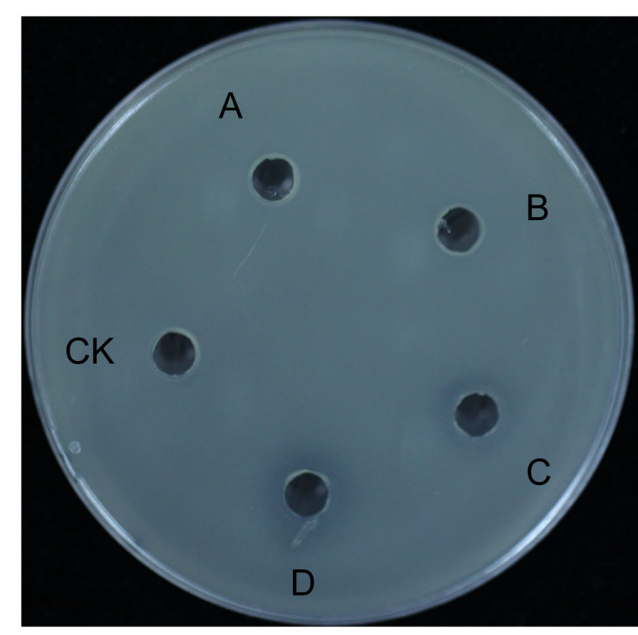

FIGURE 9 | An antagonistic assay against $A$. citrulli in vitro by surfactin standard. (CK) methanol, (A) $1 \mu \mathrm{g}$ surfactin, (B) $5 \mu \mathrm{g}$ surfactin, (C) $25 \mu \mathrm{g}$ surfactin and (D) $50 \mu \mathrm{g}$ surfactin.

evaluate the biocontrol activity. Three days after A. citrulli MH21 inoculation, the disease severity of melon seedlings that were pre-treated with PBS (control) was 58.52\% (Figure 12). Treatment of melon seedlings with cells of the wild-type strain reduced the severity of $B F B$ low to $20.37 \%$. However, treatment with same amount of the $\triangle \operatorname{srf} A B$ strain demonstrated a disease severity as high as $56.67 \%$, showed no obvious differences compared with controls (Figure 12). Accordingly, $\triangle \operatorname{srfAB}$ lost the capability of controlling BFB. Similar results were obtained 5 and 7 days post inoculation (Figure 12). These results demonstrated that surfactin produced by B. subtilis 9407 plays a major role in suppressing $A$. citrulli-induced BFB.

\section{DISCUSSION}

Biological control using microorganisms has been well known as a safe and efficient method for suppressing plant diseases (Lemos et al., 2016). In recent years, Bacillus spp., A. avenae, P. anomala, Streptomyces spp. and B. amyloliquefaciens 54 have been identified as biological control agents against BFB (Santos et al., 2006; Yaeram et al., 2006; Wang et al., 2009; Johnson et al., 2011; Jiang et al., 2015). However, the microorganisms on control of BFB is rare. To date, there are no reports about using B. subtilis as a biological control agent against BFB. Moreover, little is known about the biocontrol mechanism of microorganisms on control of BFB. In this study, B. subtilis 9407 demonstrated strong antibacterial activity against $A$. citrulli in the dual plate assay and $61.7 \%$ biocontrol efficacy on melon seedlings 4 days post inoculation under greenhouse conditions. Surfactin, which consists of C13- to C16-surfactin A, was the primary antibacterial compound of B. subtilis 9407, and it played a major role in biofilm formation, swarming motility, colonization and suppressing BFB. We propose that the biocontrol activity of B. subtilis 9407 is the results of the coordinated action of antibacterial activity

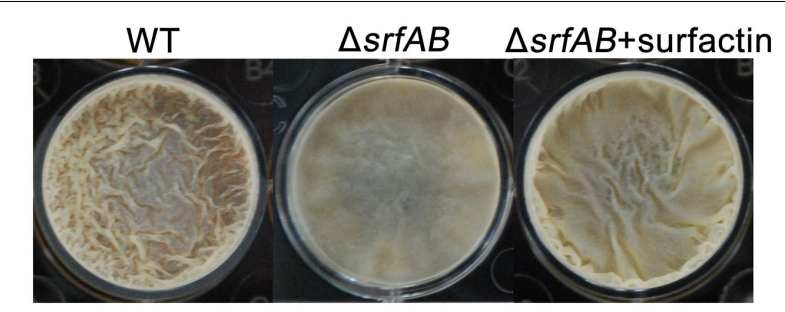

FIGURE 10 | Biofilm formation of $B$. subtilis $9407(W T)$ and $\triangle$ srfAB with or without adding exogenous surfactin. WT and $\triangle S$ sfAB were grown in MSgg medium for $72 \mathrm{~h}$ at $25^{\circ} \mathrm{C}$ in 12 -well microtiter plates and images were taken. WT formed wrinkly floating pellicles at the liquid-air interface of liquid cultures in MSgg. $\triangle$ srfAB formed thinner pellicles. The biofilm formation of $\triangle s r f A B$ was restored by adding $2 \mu \mathrm{L}$ of the commercial surfactin $(10 \mu \mathrm{g} / \mathrm{mL})$.

and colonization. This study is the first report on the use of a $B$. subtilis strain as a potential biological control agent to control $\mathrm{BFB}$ and surfactin contributes to the biocontrol of BFB.

The mechanisms of biological control of Bacillus strains have often been associated with the production of different antimicrobial compounds (Ongena and Jacques, 2008). However, the mechanisms of biocontrol of BFB by B. subtilis are not clear. In the present study, B. subtilis 9407 inhibited the growth of A. citrulli $\mathrm{MH} 21$ in vitro (Figures 1, 2). The large inhibition zones could be due to the effects of antimicrobial compounds produced by $B$. subtilis 9407 . These results suggested that the production of antibacterial compounds may be a mechanism of B. subtilis 9407 to suppress $A$. citrulli. To elucidate the mechanisms by which $B$. subtilis 9407 inhibits $A$. citrulli growth, we decided to mutate the selected candidate genes $\operatorname{srf} A B$ and $p p s B$ responsible for the synthesis of surfactin and fengycin, respectively (Zeriouh et al., 2014; Fan et al., 2017). The $\triangle \operatorname{srf} A B$ which was non-surfactin producer was almost completely defective in antibacterial activity against $A$. citrulli (Figure 4). These results suggested that surfactin may be a major antibacterial-active compound. Furthermore, the lipopeptide crude extracts from $\triangle s r f A B, \Delta p p s B$ and wild-type showed the similar results and demonstrated that surfactin was a primary active compound that led to the inhibitory effect of B. subtilis 9407 against A. citrulli (Figure 5). Surfactin has been isolated from members of the Bacillus genus, and it displays strong antimicrobial activity and inhibits the growth of a wide range of plant pathogens (Bais et al., 2004; Bacon et al., 2012). These results of this study demonstrated for the first time the antibacterial activity of surfactin against A. citrulli.

The surfactin family is comprised of three isoforms, which differ in their amino acid residue at position 7 , namely surfactin $\mathrm{A}, \mathrm{B}$ and $\mathrm{C}$ has a leucine, valine and isoleucine at position 7, respectively (Peypoux et al., 1999). Within each isoform, there are homologues differences in their branching and number of carbon atoms (Zhao et al., 2017). Different Bacillus strains produce varied surfactin. For example, surfactin $\mathrm{C}$ is the main component among Bacillus subtilis BC1212produced surfactins (Hwang et al., 2007). B. subtilis EBS05 produces a mixture of the C12- to C15-surfactin A (Wen 


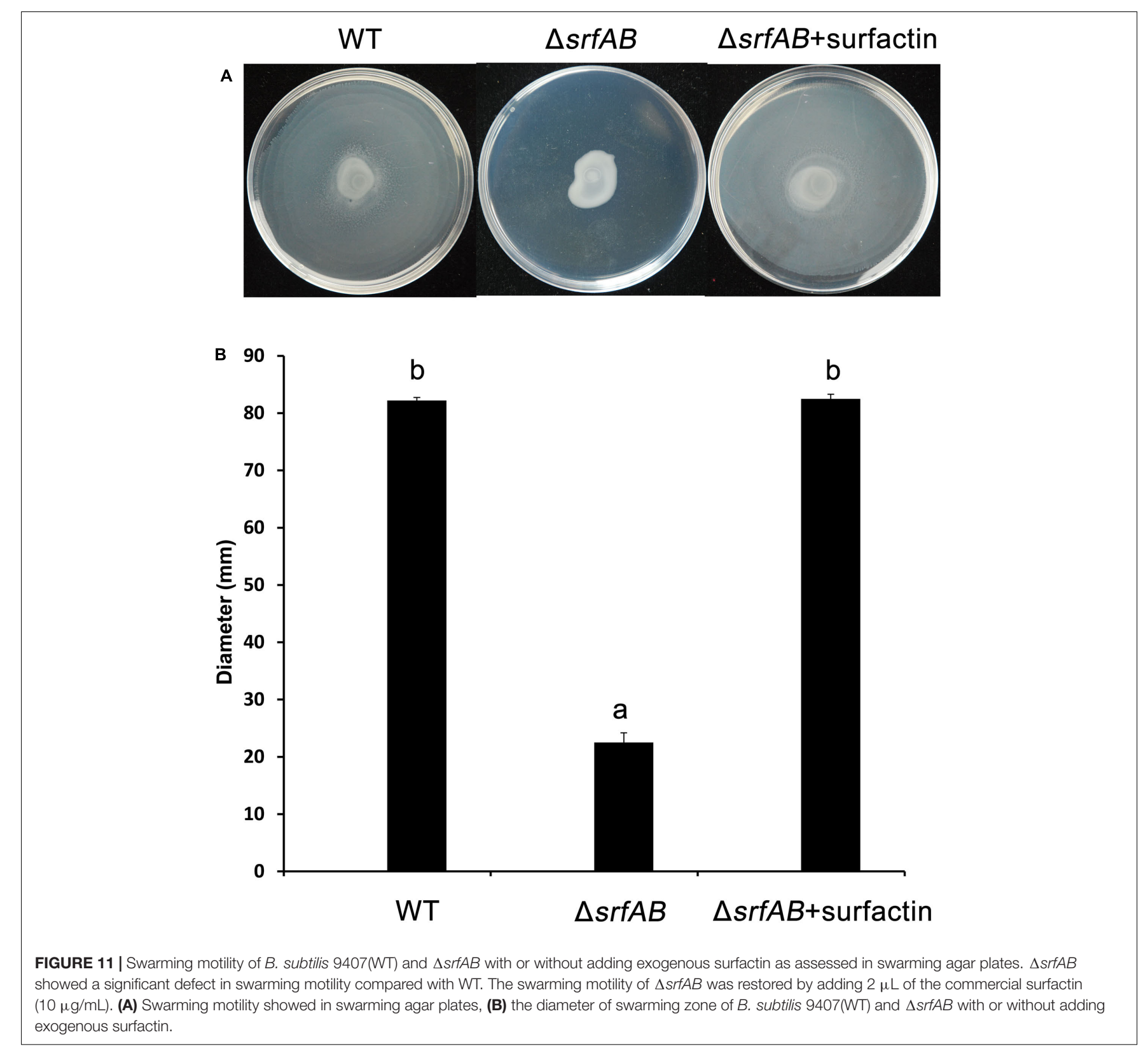

TABLE 3 | Colonization assay of wild-type B. subtilis 9407 and $\triangle$ sifAB mutant on melon leaves.

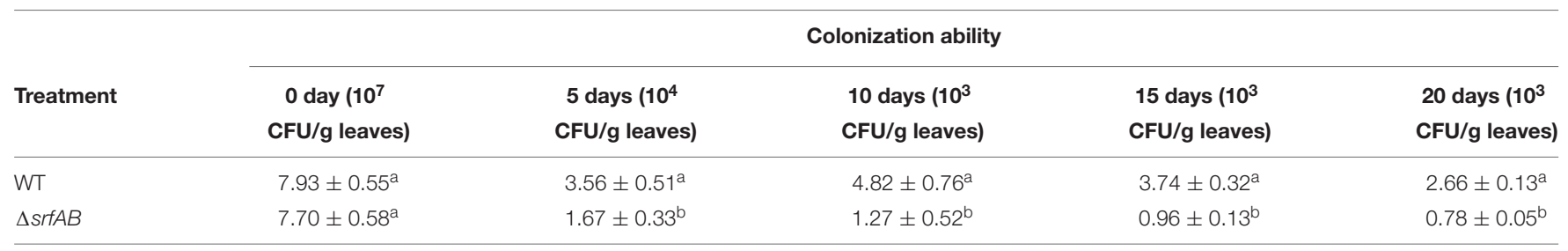

The colonization ability of wild-type B. subtilis 9407 and $\triangle$ sifAB mutant on melon leaves was determined 0-20 days post inoculation. Data are expressed as bacterial CFU per gram of leaves. The data are the average \pm standard error from three replicates. Different letters represent a significant difference at $P<0.01$.

et al., 2011). Moreover, the quantity of surfactrin produced by different Bacillus strains is different. For example, Jia et al. (2015) reported that C12-, C13- and C16-surfactin are more abundant than C14- and C15-surfactin in B. subtilis B841.
While, B. subtilis BS-37 usually produces C15-surfactin as the major component (Liu et al., 2015). Therefore, the quantity and isoforms of surfacrin are different in different members of the Bacillus genus. In this study, surfactin is a primary 
TABLE 4 | Colonization assay of wild-type B. subtilis 9407 and $\triangle$ sifAB mutant on melon roots.

\begin{tabular}{|c|c|c|c|c|c|}
\hline \multirow{3}{*}{ Treatment } & \multicolumn{5}{|c|}{ Colonization ability } \\
\hline & 0 day $\left(10^{7}\right.$ & 5 days $\left(10^{4}\right.$ & 10 days $\left(10^{4}\right.$ & 15 days $\left(10^{4}\right.$ & 20 days $\left(10^{4}\right.$ \\
\hline & CFU/g roots) & CFU/g roots ) & CFU/g roots) & CFU/g roots) & CFU/g roots) \\
\hline WT & $7.93 \pm 0.55^{\mathrm{a}}$ & $7.44 \pm 0.38^{a}$ & $2.94 \pm 0.47^{a}$ & $1.33 \pm 0.07^{a}$ & $1.02 \pm 0.05^{a}$ \\
\hline$\Delta s i f A B$ & $7.70 \pm 0.58^{a}$ & $1.89 \pm 0.19^{b}$ & $0.30 \pm 0.06^{b}$ & $0.18 \pm 0.03^{b}$ & $0.10 \pm 0.01^{b}$ \\
\hline
\end{tabular}

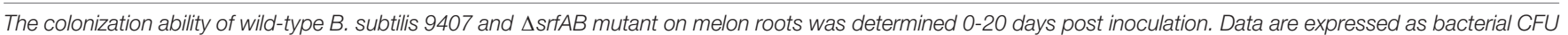
per gram of roots. The data are the average \pm standard error from three replicates. Different letters represent a significant difference at $P<0.01$.

active compound of B. subtilis 9407 against A. citrulli $\mathrm{MH} 21$ in vitro (Figures 4,5) and consists of C13- to C16-surfactin A (Figures 7, 8). At the same time, surfactin standard also showed antibacterial activity against A. citrulli MH21 (Figure 9). The difference in antibacterial activity of surfactin produced by B. subtilis 9407 and surfactin standard is required to determine. Further research is needed to determine the quantity and the exact chemical structure of the surfactin produced by B. subtilis 9407.

B. subtilis strains produce more than two dozen types of antimicrobial compounds to suppress the growth of phytopathogens (Stein, 2005). In our study, $\triangle \operatorname{srf} A B$ also had an area of thinned growth of $A$. citrulli MH21 in dual culture assay (Figures 4, 5). Moreover, $\triangle p p s B$ showed a reduced antibacterial activity against $A$. citrulli MH21 (Figures 4, 5), indicating fengycin was one of antibacterial compounds. Additionally, we also found other peptide synthesis gene clusters in the genome of B. subtilis 9407 (data not shown). These findings indicate that besides fengycin and surfactin, other antimicrobial compounds may also play a role in antagonism against $A$. citrulli. Further research is required to determine other antimicrobial compounds.

Surfactin is also well known to involve in swarming motility and trigger biofilm formation. For example, a deficiency in surfactin production of $B$. subtilis UMAF6614 led to a reduction of swarming motility and biofilm formation (Zeriouh et al., 2014). Luo et al. (2015) reported that compared with wild type of $B$. subtilis 916, $\Delta s r f$ deficient in surfactin production also showed substantially decreased in swarming motility and biofilm formation. In accordance with previous researches, we showed that $\triangle \operatorname{srf} A B$ was deficient in swarming motility and biofilm formation (Figures 10, 11), which was restored in the presence of exogenously supplemented surfactin (Figures 10, 11), indicating that surfactin plays a major role in swarming motility and biofilm formation of B. subtilis 9407.

Successful colonization of biological control agents is considered a crucial step for successful biocontrol (Chowdhury et al., 2013; Weng et al., 2013). Many studies have illustrated that surfactin plays a vital role in colonization of $B$. subtilis on plant. For example, the mutant of B. subtilis 6051, which was unable to produce surfactin, failed to colonize on Arabidopsis roots (Bais et al., 2004). Moreover, Zeriouh et al. (2014) reported that $B$. subtilis UMAF6614 colonized on melon leaves due to the production of surfactin. Similarly, in our study, B. subtilis 9407 effectively colonized on melon leaves and roots, while $\triangle \operatorname{srfAB}$ showed significantly decreased in the colonization on

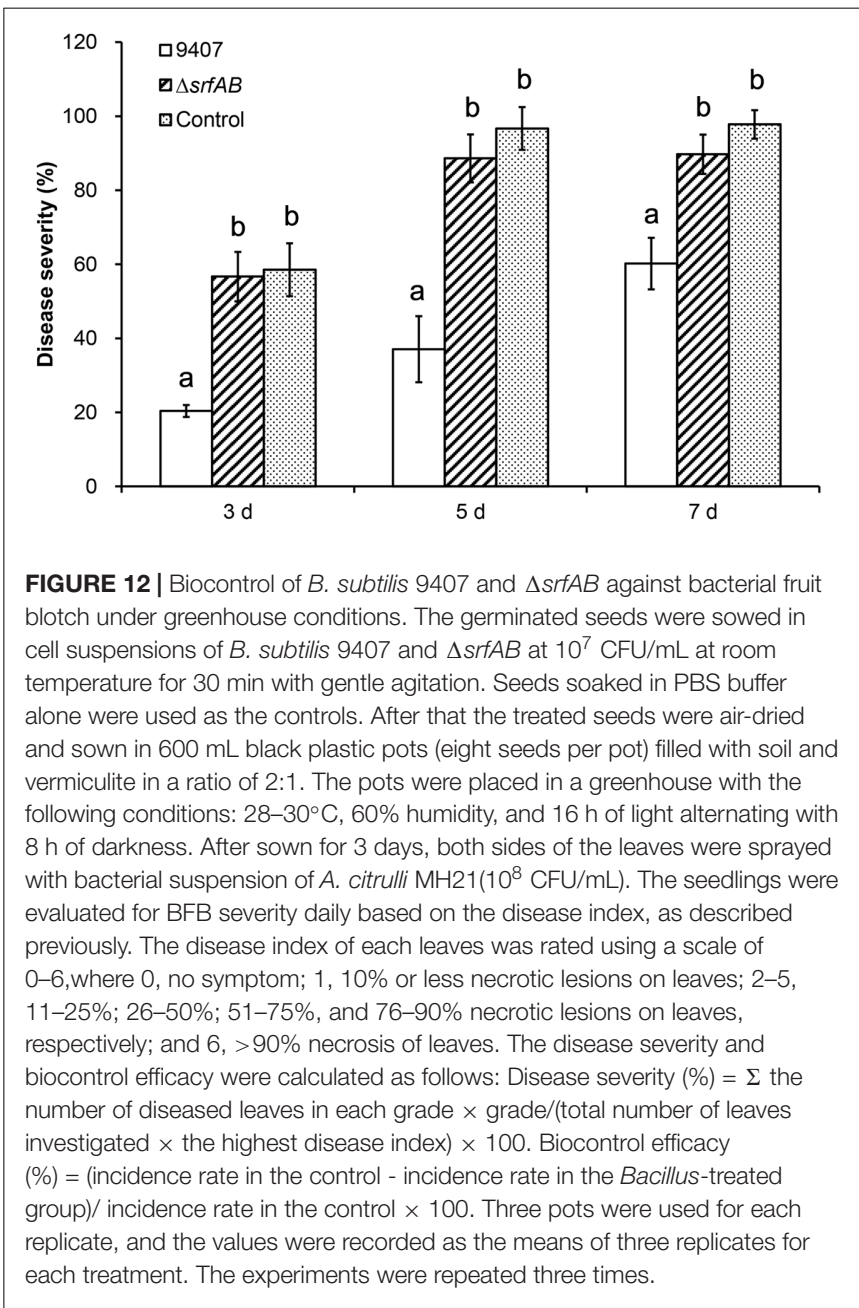

melon leaves and roots (Tables 3, 4). These results suggested that surfactin produced by B. subtilis 9407 affects the efficient colonization.

Previous studies have reported that surfactin plays essential roles in biological control of plant diseases (Alvarez et al., 2012; Deravel et al., 2014; Luo et al., 2015). However, the contribution of surfactin to the biocontrol of $\mathrm{BFB}$ in vivo is not clear. In this study, we performed biocontrol assays against $\mathrm{BFB}$ using wild type and $\triangle \operatorname{srf} A B$, and we determined that surfactin produced by B. subtilis 9407 played a major role in the biocontrol of BFB (Figure 12). Therefore, surfactin plays 
important roles in biocontrol of BFB via at least two mechanisms: as an antimicrobial agent and a stimulus for colonization. This result is consistent with previous study reporting that surfactin plays a primary role in biocontrol of tomato wilt disease by B. subtilis 3610 via at least two mechanisms describe above (Chen et al., 2013). The results of this study demonstrated for the first time the surfactin contributions to the biocontrol of BFB. So far, Bacillus spp., A. avenae, Pichia anomala, Streptomyces spp. are potential biological agents against BFB (Fessehaie and Walcott, 2005; Wang et al., 2009; Jiang et al., 2015) However, little is known about the biocontrol mechanism of them on control of BFB. Jiang et al. (2015) repoted that B. amyloliquefaciens 54 can significantly control the BFB by increasing the expression level of defense related gene PR1 and accumulation the hydrogen peroxide in the plant, when the watermelon were treated with B. amyloliquefaciens 54 at $1 \times 10^{8} \mathrm{CFU} / \mathrm{mL}$. In the present study, we propose that the biocontrol activity of B. subtilis 9407 is the results of the coordinated action of surfactin-mediated antibacterial activity and colonization, when this bacterium was used as a seed treatment at $1 \times 10^{7} \mathrm{CFU} / \mathrm{mL}$. The results of our study may provide a new biological control agent for controlling BFB and improve our understanding of the biocontrol mechanism of $B$. subtilis 9407.

\section{CONCLUSION}

In conclusion, this study reported that B. subtilis 9407 efficiently controlled BFB that was caused by $A$. citrulli in vitro and in vivo. Moreover, the surfactin produced by B. subtilis 9407 , which consisted of C13- to C16-surfactin A, was the primary antibacterial compound, and it played a major role in biofilm formation, swarming motility, colonization and biocontrol against BFB. We propose that the biocontrol activity of $B$. subtilis 9407 is the results of the coordinated action of surfactinmediated antibacterial activity and colonization. This is the first report about the use of a $B$. subtilis strain as a potential

\section{REFERENCES}

Aleti, G., Lehner, S., Bacher, M., Compant, S., Nikolic, B., Plesko, M., et al. (2016). Surfactin variants mediate species-specific biofilm formation and root colonization in Bacillus. Environ. Microbiol. 18, 2634-2645. doi: 10.1111/14622920.13405

Aleti, G., Sessitsch, A., and Brader, G. (2015). Genome mining: prediction of lipopeptides and polyketides from Bacillus and related Firmicutes. Comput. Struct. Biotechnol. J. 13, 192-203. doi: 10.1016/j.csbj.2015.03.003

Alvarez, F., Castro, M., Principe, A., Borioli, G., Fischer, S., Mori, G., et al. (2012). The plant-associated Bacillus amyloliquefaciens strains MEP218 and ARP23 capable of producing the cyclic lipopeptides iturin or surfactin and fengycin are effective in biocontrol of sclerotinia stem rot disease. J. Appl. Microbiol. 112, 159-174. doi: 10.1111/j.1365-2672.2011.05182.x

Arnaud, M., Chastanet, A., and Debarbouille, M. (2004). New vector for efficient allelic replacement in naturally nontransformable, low-GC-content, grampositive bacteria. Appl. Environ. Microbiol. 70, 6887-6891. doi: 10.1128/aem. 70.11.6887-6891.2004

Bacon, C. W., Hinton, D. M., Mitchell, T. R., Snook, M. E., and Olubajo, B. (2012). Characterization of endophytic strains of Bacillus mojavensis and their biological control agent to control BFB through the production of surfactin.

\section{AUTHOR CONTRIBUTIONS}

HF carried out the main experiments, data analysis and wrote a manuscript draft. ZZ participated in the colonization assay and biocontrol analysis of BFB under greenhouse conditions. YL participated in experimental design and revised the manuscript. $\mathrm{XZ}$ participated in the construction of $\triangle \operatorname{srfAB}$ mutant in $B$. subtilis 9407 and revised the manuscript. YD participated in the colonization assay. QW guided experimental design. All authors read and approved the final manuscript.

\section{FUNDING}

This work was financially supported by National Natural Science Foundation of China (Grant No. 31371977) and Agricultural Research Outstanding Talents and Innovation Team of Ministry of Agriculture.

\section{ACKNOWLEDGMENTS}

We thank Prof. Liqun Zhang (China Agricultural University) and Dr. Zhengguang Ren (Beijing University of Agriculture) for assistance on the biocontrol analysis experiments. We also thank Tantan Gao and other members of the QW lab for comments during the preparation of this manuscript.

\section{SUPPLEMENTARY MATERIAL}

The Supplementary Material for this article can be found online at: https://www.frontiersin.org/articles/10.3389/fmicb. 2017.01973/full\#supplementary-material

production of surfactin isomers. Biol. Control 62, 1-9. doi: 10.1016/j.biocontrol. 2012.03.006

Bahar, O., Kritzman, G., and Burdman, S. (2009). Bacterial fruit blotch of melon: screens for disease tolerance and role of seed transmission in pathogenicity. Eur. J. Plant Pathol. 123, 71-83. doi: 10.1007/s10658-0089345-7

Bais, H. P., Fall, R., and Vivanco, J. M. (2004). Biocontrol of Bacillus subtilis against infection of Arabidopsis roots by Pseudomonas syringae is facilitated by biofilm formation and surfactin production. Plant Physiol. 134, 307-319. doi: $10.1104 /$ pp.103.028712

Branda, S. S., Gonzalez-Pastor, J. E., Ben-Yehuda, S., Losick, R., and Kolter, R. (2001). Fruiting body formation by Bacillus subtilis. Proc. Natl. Acad. Sci. U.S.A. 98, 11621-11626. doi: 10.1073/pnas.191384198

Burdman, S., and Walcott, R. (2012). Acidovorax citrulli: generating basic and applied knowledge to tackle a global threat to the cucurbit industry. Mol. Plant Pathol. 13, 805-815. doi: 10.1111/j.1364-3703.2012.00810.x

Chen, X., Zhang, Y., Fu, X., Li, Y., and Wang, Q. (2016). Isolation and characterization of Bacillus amyloliquefaciens PG12 for the biological control of apple ring rot. Postharvest Biol. Technol. 115, 113-121. doi: 10.1016/j. postharvbio.2015.12.021 
Chen, Y., Chai, Y., Gu, J.-H., and Losick, R. (2012). Evidence for cyclic Di-GMPmediated signaling in Bacillus subtilis. J. Bacteriol. 194, 5080-5090. doi: 10.1128/ jb.01092-12

Chen, Y., Yan, F., Chai, Y., Liu, H., Kolter, R., Losick, R., et al. (2013). Biocontrol of tomato wilt disease by Bacillus subtilis isolates from natural environments depends on conserved genes mediating biofilm formation. Environ. Microbiol. 15, 848-864. doi: 10.1111/j.1462-2920.2012.02860.x

Chowdhury, S. P., Dietel, K., Raendler, M., Schmid, M., Junge, H., Borriss, R., et al. (2013). Effects of Bacillus amyloliquefaciens FZB42 on lettuce growth and health under pathogen pressure and its impact on the rhizosphere bacterial community. PLOS ONE 8:e68818. doi: 10.1371/journal.pone.0068818

Chowdhury, S. P., Hartmann, A., Gao, X., and Borriss, R. (2015). Biocontrol mechanism by root-associated Bacillus amyloliquefaciens FZB42-a review. Front. Microbiol. 6:780. doi: 10.3389/fmicb.2015.00780

Daguerre, Y., Siegel, K., Edel-Hermann, V., and Steinberg, C. (2014). Fungal proteins and genes associated with biocontrol mechanisms of soil-borne pathogens: a review. Fungal Biol. Rev. 28, 97-125. doi: 10.1016/j.fbr.2014.11.001

Deravel, J., Lemiere, S., Coutte, F., Krier, F., Van Hese, N., Bechet, M., et al. (2014). Mycosubtilin and surfactin are efficient, low ecotoxicity molecules for the biocontrol of lettuce downy mildew. Appl. Microbiol. Biotechnol. 98, 6255-6264. doi: $10.1007 / \mathrm{s} 00253-014-5663-1$

Falardeau, J., Wise, C., Novitsky, L., and Avis, T. J. (2013). Ecological and mechanistic insights into the direct and indirect antimicrobial properties of Bacillus subtilis lipopeptides on plant pathogens. J. Chem. Ecol. 39, 869-878. doi: 10.1007/s10886-013-0319-7

Fan, H., Ru, J., Zhang, Y., Wang, Q., and Li, Y. (2017). Fengycin produced by Bacillus subtilis 9407 plays a major role in the biocontrol of apple ring rot disease. Microbiol. Res. 199, 89-97. doi: 10.1016/j.micres.2017.03.004

Fessehaie, A., and Walcott, R. R. (2005). Biological control to protect watermelon blossoms and seed from infection by Acidovorax avenae subsp. citrulli. Phytopathology 95, 413-419. doi: 10.1094/phyto-95-0413

Gao, S., Wu, H., Yu, X., Qian, L., and Gao, X. (2016). Swarming motility plays the major role in migration during tomato root colonization by Bacillus subtilis SWR01. Biol. Control 98, 11-17. doi: 10.1016/j.biocontrol.2016.03.011

Gao, T., Foulston, L., Chai, Y., Wang, Q., and Losick, R. (2015). Alternative modes of biofilm formation by plant-associated Bacillus cereus. Microbiologyopen 4, 452-464. doi: 10.1002/mbo3.251

Ghelardi, E., Salvetti, S., Ceragioli, M., Gueye, S. A., Celandroni, F., and Senesi, S. (2012). Contribution of surfactin and SwrA to flagellin expression, swimming, and surface motility in Bacillus subtilis. Appl. Environ. Microbiol. 78, 6540-6544. doi: 10.1128/aem.01341-12

Guo, Q., Dong, W., Li, S., Lu, X., Wang, P., Zhang, X., et al. (2014). Fengycin produced by Bacillus subtilis NCD-2 plays a major role in biocontrol of cotton seedling damping-off disease. Microbiol. Res. 169, 533-540. doi: 10.1016/j. micres.2013.12.001

Hopkins, D. L., and Thompson, C. M. (2002). Seed transmission of Acidovorax avenae subsp. citrulli in cucurbits. HortScience 37, 924-926. doi: 10.1094/ MPMI- 22-8-0909

Hopkins, D. L., Thompson, C. M., Hilgren, J., and Lovic, B. (2003). Wet seed treatment with peroxyacetic acid for the control of bacterial fruit blotch and other seedborne diseases of watermelon. Plant Dis. 87, 1495-1499. doi: 10.1094/ pdis.2003.87.12.1495

Hwang, M. H., Kim, M. H., Gebru, E., Jung, B. Y., Lee, S. P., and Park, S. C. (2008). Killing rate curve and combination effects of surfactin C produced from Bacillus subtilis complex BC1212 against pathogenic Mycoplasma hyopneumoniae. World J. Microbiol. Biotechnol. 24, 2277-2282. doi: 10.1007/s11274-008-9752-0

Hwang, Y. H., Park, B. K., Lim, J. H., Kim, M. S., Park, S. C., Hwang, M. H., et al. (2007). Lipopolysaccharide-binding and neutralizing activities of surfactin C in experimental models of septic shock. Eur. J. Pharmacol. 556, 166-171. doi: 10.1016/j.ejphar.2006.10.031

Jia, K., Gao, Y. H., Huang, X. Q., Guo, R. J., and Li, S. D. (2015). Rhizosphere inhibition of cucumber fusarium wilt by different surfactin-excreting strains of Bacillus subtilis. Plant Pathol. J. 31, 140-151. doi: 10.5423/PPJ.OA.10.2014.0113

Jiang, C.-H., Wu, F., Yu, Z.-Y., Xie, P., Ke, H.-J., Li, H.-W., et al. (2015). Study on screening and antagonistic mechanisms of Bacillus amyloliquefaciens 54 against bacterial fruit blotch (BFB) caused by Acidovorax avenae subsp. citrulli. Microbiol. Res. 170, 95-104. doi: 10.1016/j.micres.2014.08.009
Johnson, K. L., Minsavage, G. V., Le, T., Jones, J. B., and Walcott, R. R. (2011). Efficacy of a nonpathogenic Acidovorax citrulli strain as a biocontrol seed treatment for bacterial fruit blotch of cucurbits. Plant Dis. 95, 697-704. doi: 10.1094/pdis-09-10-0660

Kearns, D. B., and Losick, R. (2003). Swarming motility in undomesticated Bacillus subtilis. Mol. Microbiol. 49, 581-590. doi: 10.1046/j.1365-2958.2003.03584.x

Kolter, R., and Greenberg, E. P. (2006). Microbial sciences - The superficial life of microbes. Nature 441, 300-302. doi: 10.1038/441300a

Lemos, W. J., Bovo, B., Nadai, C., Crosato, G., Carlot, M., Favaron, F., et al. (2016). Biocontrol ability and action mechanism of Starmerella bacillaris (synonym Candida zemplinina) isolated from wine musts against gray mold disease agent Botrytis cinerea on grape and their effects on alcoholic fermentation. Front. Microbiol. 7:1249. doi: 10.3389/fmicb.2016.01249

Lim, J. H., Park, B. K., Kim, M. S., Hwang, H. M., Rhee, M. H., Park, S. C., et al. (2005). The anti-thrombotic activity of surfactins. J. Vet. Sci. 6, 353-355.

Liu, Q., Lin, J., Wang, W., Huang, H., and Li, S. (2015). Production of surfactin isoforms by Bacillus subtilis BS-37 and its applicability to enhanced oil recovery under laboratory conditions. Biochem. Eng. J. 93, 31-37. doi: 10.1016/j.bej.2014. 08.023

Luo, C., Zhou, H., Zou, J., Wang, X., Zhang, R., Xiang, Y., et al. (2015). Bacillomycin $\mathrm{L}$ and surfactin contribute synergistically to the phenotypic features of Bacillus subtilis 916 and the biocontrol of rice sheath blight induced by Rhizoctonia solani. Appl. Microbiol. Biotechnol. 99, 1897-1910. doi: 10.1007/s00253-0146195-4

Ongena, M., and Jacques, P. (2008). Bacillus lipopeptides: versatile weapons for plant disease biocontrol. Trends Microbiol. 16, 115-125. doi: 10.1016/j.tim.2007. 12.009

Pérez, E., Rubio, M. B., Cardoza, R. E., Gutiérrez, S., Bettiol, W., Monte, E., et al. (2015). The importance of chorismate mutase in the biocontrol potential of Trichoderma parareesei. Front. Microbiol. 6:1181. doi: 10.3389/fmicb.2015. 01181

Peypoux, F., Bonmatin, J., and Wallach, J. (1999). Recent trends in the biochemistry of surfactin. Appl. Microbiol. Biot. 51, 553-563. doi: 10.1007/s002530051432

Popovic, T., and Ivanovic, Z. (2015). Occurrence of Acidovorax citrulli causing bacterial fruit blotch of watermelon in Serbia. Plant Dis. 99, 886-886. doi: 10.1094/pdis-12-14-1276-pdn

Rahman, A., Uddin, W., and Wenner, N. G. (2015). Induced systemic resistance responses in perennial ryegrass against Magnaporthe oryzae elicited by semipurified surfactin lipopeptides and live cells of Bacillus amyloliquefaciens. Mol. Plant Pathol. 16, 546-558. doi: 10.1111/mpp.12209

Ren, Z. G., Jiang, W. J., Ni, X. Y., Lin, M., Zhang, W., Tian, G. Z., et al. (2014). Multiplication of Acidovorax citrulli in planta during infection of melon seedlings requires the ability to synthesize leucine. Plant Pathol. 63, 784-791. doi: $10.1111 /$ ppa.12156

Romero, D. (2013). Bacterial determinants of the social behavior of Bacillus subtilis. Res. Microbiol. 164, 788-798. doi: 10.1016/j.resmic.2013.06.004

Sabate, D. C., and Audisio, M. C. (2013). Inhibitory activity of surfactin, produced by different Bacillus subtilis subsp. subtilis strains, against Listeria monocytogenes sensitive and bacteriocin-resistant strains. Microbiol. Res. 168, 125-129. doi: 10.1016/j.micres.2012.11.004

Sambrook, J., and Russell, D. W. (2001). Molecular Cloning: A Laboratory Manual. Cold Spring Harbor, NY: Cold Spring Harbor Laboratory Press.

Santos, E. R., Gouveia, E. R., Mariano, R. L. R., and Souto-Maior, A. M. (2006). Biocontrol of bacterial fruit blotch of melon by bioactive compounds produced by Bacillus spp. Summa Phytopathol. 32, 376-378. doi: 10.1590/ s0100-54052006000400010

Schaad, N. W., Postnikova, E., Sechler, A., Claflin, L. E., Vidaver, A. K., Jones, J. B., et al. (2008). Reclassification of subspecies of Acidovorax avenae as A. Avenae (Manns 1905) emend., A. cattleyae (Pavarino, 1911) comb. nov., A. citrulli Schaad et al., 1978) comb. nov., and proposal of A. oryzae sp. nov. Syst. Appl. Microbiol. 31, 434-446. doi: 10.1016/j.syapm.2008.09.003

Stein, T. (2005). Bacillus subtilis antibiotics: structures, syntheses and specific functions. Mol. Microbiol. 56, 845-857. doi: 10.1111/j.1365-2958.2005. 04587.x

Vollenbroich, D., Ozel, M., Vater, J., Kamp, R. M., and Pauli, G. (1997). Mechanism of inactivation of enveloped viruses by the biosurfactant surfactin from Bacillus subtilis. Biologicals 25, 289-297. doi: 10.1006/biol.1997.0099 
Wang, H., Han, L., Feng, J., and Zhang, X. (2015). Evaluation of two Streptomyces spp. and compost for growth promotion and biocontrol potential against Rhizoctonia solani on pepper. Biocontrol Sci. Techn. 25, 852-857. doi: 10.1080/ 09583157.2015.1015485

Wang, X., Li, G., Jiang, D., and Huang, H.-C. (2009). Screening of plant epiphytic yeasts for biocontrol of bacterial fruit blotch (Acidovorax avenae subsp citrulli) of hami melon. Biol. Control 50, 164-171. doi: 10.1016/j.biocontrol.2009.03.009

Wang, Y., Wang, H., Yang, C.-H., Wang, Q., and Mei, R. (2007). Two distinct manganese-containing superoxide dismutase genes in Bacillus cereus: their physiological characterizations and roles in surviving in wheat rhizosphere. FEMS Microbiol. Lett. 272, 206-213. doi: 10.1111/j.1574-6968.2007. 00759.x

Wen, C.-Y., Yin, Z.-G., Wang, K.-X., Chen, J.-G., and Shen, S.-S. (2011). Purification and structural analysis of surfactin produced by endophytic Bacillus subtilis EBS05 and its antagonistic activity against Rhizoctonia cerealis. Plant Pathol. J. 27, 342-348. doi: 10.5423/ppj.2011.27.4.342

Weng, J., Wang, Y., Li, J., Shen, Q., and Zhang, R. (2013). Enhanced root colonization and biocontrol activity of Bacillus amyloliquefaciens SQR9 by abrB gene disruption. Appl. Microbiol. Biotechnol. 97, 8823-8830. doi: 10.1007/ s00253-012-4572-4

Wu, L., Wu, H., Chen, L., Yu, X., Borriss, R., and Gao, X. (2015). Difficidin and bacilysin from Bacillus amyloliquefaciens FZB42 have antibacterial activity against Xanthomonas oryzae rice pathogens. Sci. Rep. 5:12975. doi: 10.1038/ srep12975

Yaeram, C., Thummabenjapone, P., and Pachinburavan, A. (2006). Suitable medium for increasing biomass of antagonistic Streptomyces spp. against bacterial fruit blotch disease of watermelon. Khon Kaen Agric. 34, 12-19.

Yan, F., Yu, Y., Wang, L., Luo, Y., Guo, J.-h, and Chai, Y. (2016). The comER gene plays an important role in biofilm formation and sporulation in both Bacillus subtilis and Bacillus cereus. Front. Microbiol. 7:1025. doi: 10.3389/fmicb.2016. 01025
Yaryura, P. M., Leon, M., Correa, O. S., Kerber, N. L., Pucheu, N. L., and Garcia, A. F. (2008). Assessment of the role of chemotaxis and biofilm formation as requirements for colonization of roots and seeds of soybean plants by Bacillus amyloliquefaciens BNM339. Curr. Microbiol. 56, 625-632. doi: 10.1007/s00284008-9137-5

Zeriouh, H., de Vicente, A., Perez-Garcia, A., and Romero, D. (2014). Surfactin triggers biofilm formation of Bacillus subtilis in melon phylloplane and contributes to the biocontrol activity. Environ. Microbiol. 16, 2196-2211. doi: 10.1111/1462-2920.12271

Zeriouh, H., Romero, D., Garcia-Gutierrez, L., Cazorla, F. M., de Vicente, A., and Perez-Garcia, A. (2011). The iturin-like lipopeptides are essential components in the biological control arsenal of Bacillus subtilis against bacterial diseases of cucurbits. Mol. Plant Microbe Interact. 24, 1540-1552. doi: 10.1094/mpmi-0611-0162

Zhao, H., Shao, D., Jiang, C., Shi, J., Li, Q., Huang, Q., et al. (2017). Biological activity of lipopeptides from Bacillus. Appl. Microbiol. Biotechnol. 101, 5951-5960. doi: 10.1007/s00253-017-8396-0

Conflict of Interest Statement: The authors declare that the research was conducted in the absence of any commercial or financial relationships that could be construed as a potential conflict of interest.

The reviewer JL declared a past co-authorship with several of the authors (YL and QW) to the handling Editor.

Copyright (c) 2017 Fan, Zhang, Li, Zhang, Duan and Wang. This is an open-access article distributed under the terms of the Creative Commons Attribution License (CC BY). The use, distribution or reproduction in other forums is permitted, provided the original author(s) or licensor are credited and that the original publication in this journal is cited, in accordance with accepted academic practice. No use, distribution or reproduction is permitted which does not comply with these terms. 